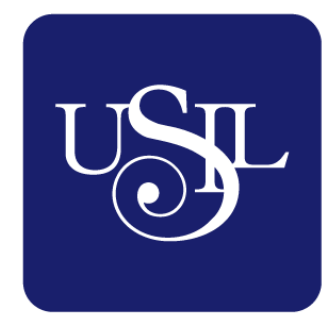

UNIVERSIDAD

SAN IGNACIO

DE LOYOLA

ESCUELA DE POSTGRADO

DOCTORADO EN NUTRICIÓN

\title{
SÍNTOMAS DE INTOLERANCIA A LA LACTOSA EN CONSUMIDORES DE LECHE DESLACTOSADA COMPARADA CON LA LECHE SIN LACTOSA DEL HOSPITAL HIPÓLITO UNANUE DEL 2015
}

Tesis para optar el Grado de Doctor en Nutrición YOUMI PAZ OLIVAS

Asesor:

Dr. Carlos Alvarado-Ortiz Ureta

Lima - Perú

2018 


\title{
ASESOR
}

Departamento Académico de Ciencias de la Salud

Universidad San Ignacio de Loyola

\author{
Miembros del Jurado \\ Presidente \\ Secretario \\ Vocal
}




\section{DEDICATORIA}

A mi familia por el apoyo incondicional. 


\section{AGRADECIMIENTOS}

A todas las personas que Dios puso en mi camino para hacer realidad un sueño más de mi vida. 


\section{RESUMEN}

Introducción: La intolerancia a la lactosa afecta al 70\% de la población mundial. La lactosa favorece la absorción de calcio y puede actuar como un prebiótico. Objetivo: Determinar si existen diferencias de los síntomas y signos característicos de la intolerancia a la lactosa en pacientes de 16 a 30 años de los grupos al que se le administró leche deslactosada comparado con leche sin lactosa. Método: Ensayo clínico aleatorizado controlado doble ciego, de equivalencia, diseño paralelo con dos grupos, a cada grupo se asignó aleatoriamente a 25 pacientes de uno u otro sexo, al grupo de intervención se le administró leche deslactosada conteniendo 15\% de lactosa y al grupo de control leche sin lactosa, el efecto se evaluó mediante un cuestionario de síntomas y signos de intolerancia a la lactosa validado por expertos. Se estimó la magnitud de las diferencias de ambos grupos mediante la prueba de $\mathrm{T}$ de Student. Resultados: El 76\% de los participantes fueron del sexo femenino, la edad promedio de los participantes fue 26 años $\pm 3,97$, en el grupo experimental el $100 \%$ de los participantes no consumían leche. En la prueba de comparación de grupos se rechazó la hipótesis nula de que las diferencias fuesen mayor del $10 \%$, siendo la diferencia obtenida de $9 \%$ que estuvo dentro del margen de equivalencia de un $10 \%$ como máximo para ambos tratamientos que se considera clínicamente aceptable, siendo el $\mathrm{p}<0,05$ para cada uno de los síntomas y signos de intolerancia a la lactosa.

Conclusiones: Se ha demostrado que la intervención con leche deslactosada conteniendo $15 \%$ de lactosa es lo suficientemente similar al grupo control, podemos considerarlo como equivalente desde el punto de vista clínico y estadístico

Palabras Claves: Intolerancia a la lactosa, leche deslactosada, leche sin lactosa. 


\section{ABSTRACT}

Introduction: Lactose intolerance affects $70 \%$ of the world's population. Lactose promotes calcium absorption and can act as a prebiotic. Objective: To determine whether there are differences in the symptoms and signs characteristic of lactose intolerance in patients aged 16 to 30 years of the groups to which removal of lactose milk was administered compared with lactose-free milk. Method:Randomized doubleblind controlled clinical trial of equivalence, parallel design with two groups, each group was randomly allocated to 25 patients of either sex, the intervention group was administered removal of lactose milk containing $15 \%$ of lactose and the group of Control lactose-free milk, the effect was assessed by a questionnaire of symptoms and signs of lactose intolerance validated by experts. The magnitude of the differences in both groups was estimated by the T Student test. Results: $76 \%$ of the participants were of the fem sex, the average age of the participants was 26 years \pm 3.97 , in the experimental group $100 \%$ of the participants did not consume milk. In the comparison test of groups is rejected the null hypothesis that the differences were greater than $10 \%$, the difference being obtained from 9 percent that was within the margin of equivalence of a $10 \%$ maximum for both treatments that are considered clinically acceptable, being $p<0.05$ for each of the symptoms and signs of lactose intolerance.

Conclusions: It has been shown that the intervention with removal of lactose milk containing $15 \%$ of lactose is sufficiently similar to the control group; we can consider it as equivalent from the clinical and statistical point of view.

Keywords: Lactose intolerance, removal of lactose milk, lactose-free milk. 


\section{İNDICE DE CONTENIDO}

\section{INTRODUCCIÒN}

\section{CAPİTULO I}

1.1 Problema de investigación 01

$\begin{array}{ll}\text { 1.1.1 Planteamiento del problema } & 01\end{array}$

$\begin{array}{ll}1.1 .2 \text { Formulación del problema } & 02\end{array}$

1.1.3 Justificación de la investigación 03

1.2 Marco referencial 04

$\begin{array}{ll}\text { 1.2.1 Antecedentes } & 04\end{array}$

1.2.2 Marco teórico 06

1.3 Objetivos e hipótesis $\quad 27$

1.3.1 Objetivo General 27

1.3.2 Objetivos Específicos $\quad 27$

$\begin{array}{ll}1.3 .3 \text { Hipótesis } & 27\end{array}$

CAPITULO II

MĖTODO 28

2.1 Tipo y diseño de investigación 28

2.2 Variables 31

2.3 Población y muestra 31

2.4 Criterios de selección 32

2.5 Instrumentos de investigación 34

2.6. Validación de cuestionarios con expertos 34

2.7 Técnicas y procedimientos de recolección 34

2.8 Análisis de datos $\quad 35$

\section{CAPITULO III}

RESULTADOS $\quad 37$

$\begin{array}{lll}3.1 & \text { Resultados } & 37\end{array}$

3.2 Discusión $\quad 45$

$\begin{array}{lll}3.3 & \text { Conclusiones } & 47\end{array}$

$\begin{array}{lll}3.4 & \text { Recomendaciones } & 48\end{array}$

$\begin{array}{lr}\text { REFERENCIAS BIBLIOGRÀFICAS } & 49\end{array}$

ANEXOS 58

Instrumentos de investigación $\quad 59$

$\begin{array}{ll}\text { Matriz de consistencia } & 65\end{array}$ 


\section{İNDICE DE TABLAS}

Tabla 1.

Composición general de la leche en diferentes especies lactosa y presentar cuadro clínico

Tabla 2.

Operacionalización de variables.

Tabla 3.

Participantes que consumen leche según grupo de evaluación

Tabla 4.

Intensidad de síntomas y signos de intolerancia evaluada en el primer día de la administración de las leches ofrecidas.

Tabla 5.

Intensidad de síntomas de intolerancia a la lactosa según grupos evaluados Tabla 6.

Nivel de significancia de cada síntoma de intolerancia a la lactosa aplicando prueba de T-student. 


\section{İNDICE DE FIGURAS}

$\begin{array}{ll}\text { Figura } 1 . & 07\end{array}$

Estructura química de la glucosa

$\begin{array}{ll}\text { Figura } 2 . & 07\end{array}$

Carbonilos y oxidrilos en la glucosa.

Figura $3 . \quad 08$

Estructura química de la fructosa

$\begin{array}{ll}\text { Figura } 4 . & 08\end{array}$

Estructura química de la galactosa

Figura $5 . \quad 09$

Estructura química de la lactosa

Figura 6.

Metabolismo de la lactosa

Figura 7.

Ruta del metabolismo de la lactosa.

Figura 8.

Superposición clínica entre la alergia a la leche de vaca y la intolerancia a la lactosa.

Figura 9.

Distribución de personas según sexo en los grupos control y experimental

Figura 10.

Tipo de leche consumida por las personas que indicaron consumir leche según grupo

Figura 11.

Motivos por lo cual las personas de los grupos evaluados indicaron no consumir leche

Figura 12.

Distribución de participantes que presentaron síntomas de intolerancia a la lactosa al consumir leche deslactosada y leche sin 
lactosa 


\section{INTRODUCCIÓN}

\section{CAPITULO I}

\subsection{PROBLEMA DE INVESTIGACIÒN \\ 1.1.1 Planteamiento del problema}

La lactosa es el "azúcar natural de la leche". Algunas personas sin saberlo presentan "intolerancia a la lactosa", caracterizada por la dificultad para digerir en el intestino delgado a la lactosa, debido a que tienen poca o nula presencia de la enzima lactasa (la responsable de transformar a la lactosa en sus unidades básicas glucosa y galactosa) generando malestares ${ }^{1}$.

En un sujeto intolerante, la lactosa sin digerir o digerida parcialmente, no se absorbe en el intestino delgado, pasa al intestino grueso, sin descomponerse, donde las bacterias la fermentan y provocan todos los síntomas característicos de la intolerancia como el dolor y la hinchazón abdominal, gases (meteorismo), náuseas y vómitos. Los síntomas se manifiestan por el consumo de productos como la leche, yogurt y queso porque contienen lactosa. ${ }^{2}$.

La deficiencia en lactasa en los adultos es un fenómeno de desarrollo congénito (muy raro), primario (de inicio tardío y desarrollo progresivo con los años) y secundario (debido a enfermedades parasitarias, ingesta de antiinflamatorios no esteroideos, antibióticos, enfermedad celiaca, entre otros). La persistencia de la lactasa es más común en las poblaciones que se dedican a la ganadería y la producción lechera, y esta a su vez se relaciona a la selección genética de los individuos con la capacidad de digerir la lactosa ${ }^{3}$.

De acuerdo con algunas estimaciones, aproximadamente el $70 \%$ de la población mundial tiene una intolerancia primaria a la lactosa ${ }^{4}$. En Sudamérica, África y Asia, alrededor del $50 \%$ de la población reportó tener una intolerancia a la lactosa y en algunos lugares la incidencia llega hasta el $100 \%$. 
En los individuos diagnosticados como intolerantes a la lactosa, evitar los productos que contienen lactosa como la leche y los lácteos, puede aliviar los síntomas. Sin embargo, la mayoría de las personas puede tolerar algunos productos lácteos y aumentar progresivamente su tolerancia. El panel de expertos de la European Food Safety Authority ${ }^{5}$, ha indicado que no es posible determinar un umbral único para el desarrollo de los síntomas en todos los intolerantes a la lactosa, debido a la gran variación individual. Aunque la bibliografía indica que los síntomas de intolerancia a la lactosa se presentan después del consumo de 6 gramos de lactosa, el panel concluyó que la gran mayoría de los sujetos con intolerancia a la lactosa puede tolerar hasta 12 gramos de lactosa como una dosis única (en particular si se toma con los alimentos) con síntomas leves o sin la presencia de estos y con dosis más altas, como de 24 gramos si se distribuyen durante el día.

La industria alimentaria ha desarrollado productos que ayudan a evitar las molestias de la intolerancia a la lactosa, así es que podemos encontrar en nuestro medio, productos reducidos o libres de lactosa (leche "deslactosada" si tiene 85\% de reducción de lactosa y leche "sin lactosa" si tiene más del 95\% de reducción de la lactosa).

En el Perú las investigaciones acerca del nivel de tolerancia a la lactosa son limitadas, por lo que no es posible indicar los parámetros máximos tolerados por el común de los peruanos.

\subsubsection{Formulación del problema}

\section{Problema general.}

¿Existe diferencias de los síntomas y signos característicos de la intolerancia a la lactosa en los pacientes jóvenes intolerantes a la lactosa de 16 a 30 años del grupo al que se le administra leche deslactosada y el grupo al que se le administra leche sin lactosa del Hospital Hipólito Unanue en el 2015? 


\section{Problemas específicos.}

- ¿Cuál es la frecuencia de los síntomas y signos característicos de la intolerancia a la lactosa en los pacientes de 16 a 30 años en el grupo al que se le administra leche deslactosada del Hospital Hipólito Unanue en el 2015?

- ¿Cuál es la frecuencia de los síntomas y signos característicos de la intolerancia a la lactosa en los pacientes de 16 a 30 años en el grupo al que se le administra leche sin lactosa del Hospital Hipólito Unanue en el 2015?

- ¿Cuáles son las características sociodemográficas de los pacientes de 16 a 30 años en los grupos de intervención y de control del Hospital Hipólito Unanue en el 2015?

\subsubsection{Justificación de la investigación}

La insuficiente ingesta de leche y productos lácteos de los pacientes con intolerancia a la lactosa influye en la absorción de calcio y por ende en el metabolismo óseo. Independiente de la edad y el género, esto lleva a una disminución en la masa ósea, seguido de aumentos en los marcadores de recambio óseo y niveles séricos de la Hormona Paratiroidea (PTH). El diagnóstico temprano de deficiencia en lactasa y la corrección dietética de la baja ingesta de calcio y el estado de la vitamina $D$ serían importantes para la prevención de daño en el metabolismo óseo y el temprano desarrollo de osteoporosis ${ }^{6}$.

Respecto a la conveniencia y utilidad, el presente estudio sirve para comprobar que la administración de leche deslactosada a los adultos jóvenes, brinda beneficios en la absorción de calcio en el intestino y puede actuar como un prebiótico.

Tiene trascendencia en la sociedad porque existen muchas personas que no consumen leche porque no tienen el conocimiento sobre los beneficios de la lactosa y el presente estudio permite conocer las bondades de la lactosa en las proporciones adecuadas como leche deslactosada al 15\%.

Respecto a las implicancias prácticas este estudio ayudará a resolver un problema real, la intolerancia a la lactosa que presentan la mayoría de personas de nuestro país. 
El presente estudio tiene un valor teórico porque en el ámbito nacional son escasos los estudios encontrados. En nuestro medio existen limitadas publicaciones acerca de la intolerancia a la lactosa en la población peruana, asimismo no existe un estudio que compare los niveles de tolerancia en personas intolerantes a la lactosa entre un producto reducido en lactosa y uno relativamente sin lactosa.

Los resultados obtenidos contribuyen no sólo en llenar un vacío en el conocimiento sino permite establecer líneas de investigación respecto a la importancia de la lactosa en la alimentación.

El estudio sirve también para que otros investigadores del país puedan replicar la presente investigación en otros grupos etarios y otras poblaciones.

Respecto a la utilidad metodológica el presente estudio aportó un instrumento para medir la variable de respuesta constituida por síntomas y signos que se manifiestan por la intolerancia a la lactosa.

Ante la necesidad de la información el presente estudio permitirá conocer que la leche deslactosada conteniendo $15 \%$ de lactosa es similar a la leche sin lactosa en lo referente a la presentación de síntomas y signos de intolerancia a la lactosa.

\subsection{MARCO REFERENCIAL}

\subsubsection{Antecedentes}

En la bibliografía podemos encontrar diversos estudios acerca de los niveles tolerables de lactosa en personas intolerantes.

El cuadro clínico (síntomas y signos) característico que presentan las personas con deficiencia en lactasa cuando consumen leche o sus derivados consta de: dolor abdominal, diarrea, náuseas, flatulencia y/o meteorismo, en relación a la ingesta de lactosa. Los síntomas pueden variar en cada individuo dependiendo de la cantidad de lactosa ingerida, el grado de intolerancia y el tipo de alimento consumido ${ }^{5}$.

Según un artículo titulado Milk and dairy products in human nutrition realizado por la Organización de las Naciones Unidas para la Agricultura y Alimentación ${ }^{1}$ en Sudamérica, África y Asia, por encima del $50 \%$ de la población reportaron tener una disminución en la actividad de la enzima lactasa (intolerancia a la lactosa primaria), 
además señalaron que a pesar de ello los productos derivados de la leche fermentada como el yogur han mostrado ser bien tolerados por personas con intolerancia a la lactosa. Este antecedente indica que productos como el yogur que naturalmente contiene alrededor de 4 a $5 \mathrm{~g}$ de lactosa puede ser bien aceptado por personas con intolerancia primaria a la lactosa.

En el Nutrition and Allergies, Scientific Opinion on lactose thresholds' in lactose intolerance and galactosaemia realizado por la Autoridad Europea de Seguridad Alimentaria ${ }^{5}$ indicó que la cantidad de lactosa necesaria para desarrollar el cuadro clínico es más de 12 gramos en una sola dosis con poco o ningún síntoma. Cantidades mayores a 24 gramos de lactosa podrían ser toleradas si son distribuidos durante el día. Así las personas que padecen de intolerancia a la lactosa deben tener en cuenta el aporte de lactosa de la leche y de sus derivados, además de la forma de fragmentarla en su ingesta.

Así por ejemplo en un estudio reciente, los tratamientos sintomáticos de la intolerancia a la lactosa en los niños fueron una dieta libre de lactosa o una dieta con poca lactosa. La dieta libre de lactosa solo fue necesaria en los casos de una deficiencia congénita de la enzima lactasa en niños. En todas las otras situaciones clínicas, alguna actividad de la enzima lactasa persistió y cantidades "pequeñas" de lactosa fueron toleradas. Alrededor de 0,5 a 7,0g de lactosa han demostrado no causar síntomas y algunos intolerantes han demostrado poder aceptar entre 240 a $500 \mathrm{ml}$ de leche por día?

Diversos estudios sobre pacientes diagnosticados como intolerantes a la lactosa, se indican como parte de su tratamiento, a los lácteos reducidos en lactosa los que han demostrado no causar o generar mínimos síntomas.

Diferentes estudios, como el que fue realizado por Mark Fox, recomiendan como parte del tratamiento de la intolerancia a la lactosa, la reducción de la ingesta de lactosa en lugar de la exclusión de ésta, porque se ha demostrado que la mayoría de pacientes pueden ingerir al menos $12 \mathrm{~g}$ lactosa (equivalente a $250 \mathrm{ml}$ de leche) sin experimentar síntomas, y si se toma con otros alimentos, hasta $18 \mathrm{~g}$ de lactosa" ${ }^{2}$. 
Otro estudio titulado Intolerancia a la lactosa y productos lácteos realizado por Vénica, indica que se debe optimizar la ingesta de leche, sabiendo que hay personas que no presentan síntomas cuando esta es ingerida con otros nutrientes ${ }^{9}$.

\subsubsection{Marco teórico}

\section{Carbohidratos.}

Los carbohidratos constituyen el grupo de nutrientes o compuestos orgánicos más numeroso en la naturaleza, químicamente contienen varios grupos oxidrilo (alcohol) y un grupo aldehído o acetona. Pueden ser azúcares simples (monosacáridos), formados por dos estructuras (disacáridos) o sus polímeros (oligosacáridos y polisacáridos $)^{10}$.

Los carbohidratos se clasifican en:

\section{Monosacáridos.}

Los monosacáridos son los glúcidos más sencillos se clasifican según el número de átomos de carbono que tengan la molécula, se denominan triosas, tetrosas, pentosas y hexosas ${ }^{11}$. Los monosacáridos más importantes desde el punto de vista biológico son las hexosas y se clasifican en:

a. Glucosa: tiene seis átomos de carbono, es la molécula que utiliza las células para obtener energía y llevar a cabo sus funciones fisiológicas ${ }^{11}$.

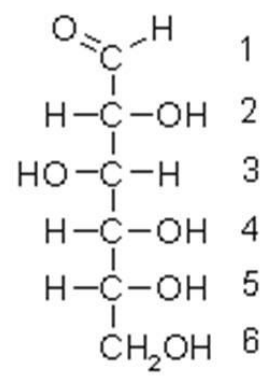

Estructura abierta

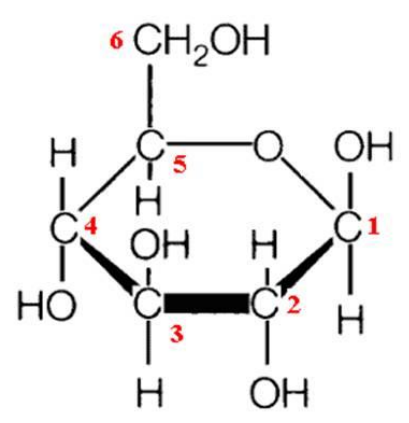

Estructura cíclica 
Figura 1. Estructura química de la glucosa

Fuente: Estructura química de la glucosa. Tomado de "Química General: Biomoléculas," por la Pontificia Universidad Católica del Perú (PUCP), 2011. Recuperado de:

http://corinto.pucp.edu.pe/quimicageneral/contenido/73-biomoleculas.html

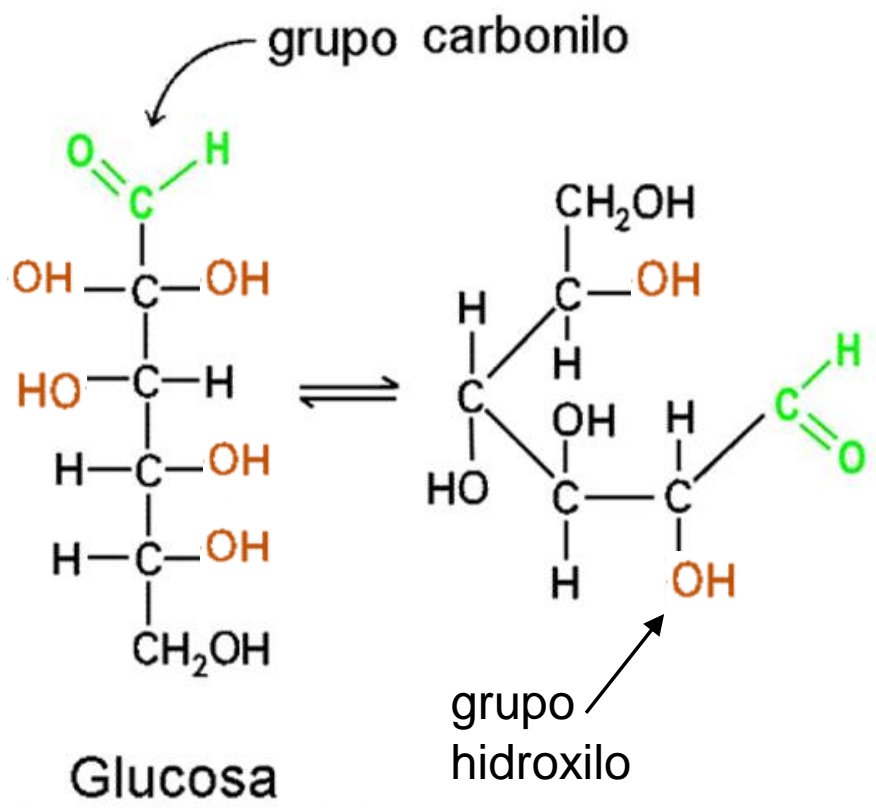

Figura 2. Glucosa.

b. Fructosa: se encuentra también en las frutas y la miel de abeja. Es el más dulce de los azúcares. Después de ser absorbida en el intestino, pasa al hígado donde es rápidamente metabolizada a glucosa ${ }^{11}$. 


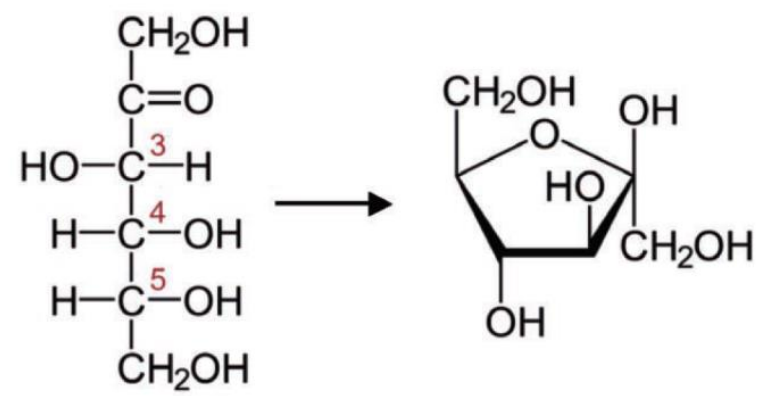

Figura 3. Estructura química de la fructosa

c. Galactosa: no se encuentra libre en la naturaleza, forma parte de la lactosa y es producida por su hidrólisis ${ }^{11}$.

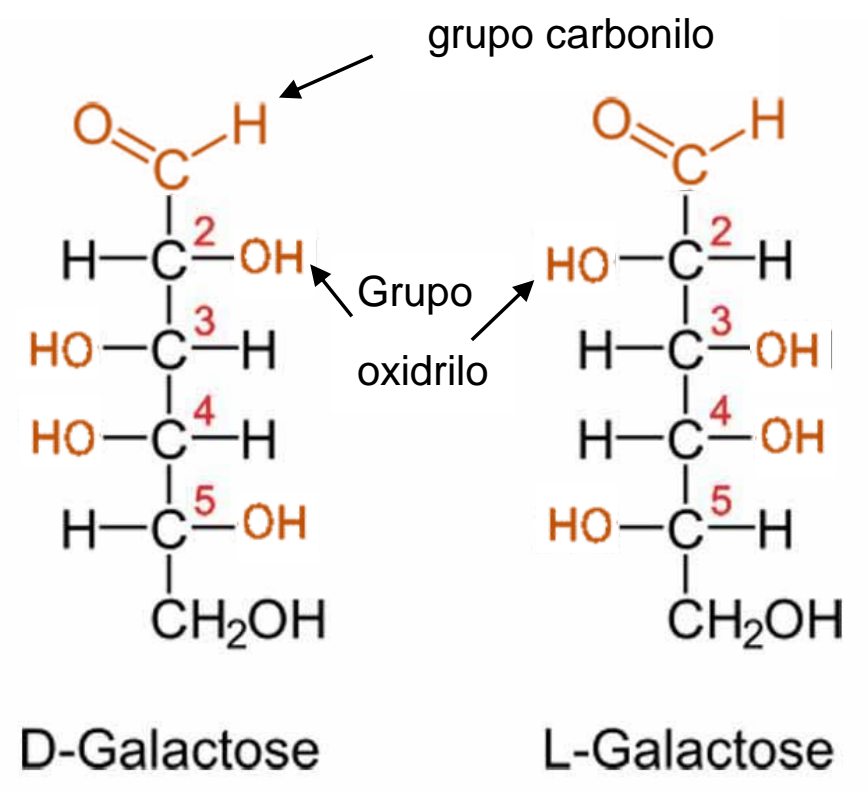

Figura 4. Estructura química de la galactosa

\section{Disacáridos.}

Son glúcidos relativamente complejos formados por la unión de dos monosacáridos, esta unión se produce al reaccionar un grupo aldehído o un grupo cetónico de un 
monosacárido con un grupo hidroxilo del otro, obteniéndose el disacárido y una molécula de agua ${ }^{11}$.

Los disacáridos más importantes son:

- Sacarosa: formada por la unión de una molécula de glucosa y una de fructuosa. Es el azúcar que utilizamos en la alimentación procede de la caña de azúcar y de la remolacha azucarera ${ }^{11}$.

- Maltosa: formada por la unión de dos moléculas de glucosa. Es el producto de la digestión del almidón ${ }^{11}$.

- Lactosa: formada por la unión de una molécula de glucosa más una de galactosa. Es el azúcar de la leche ${ }^{11}$.

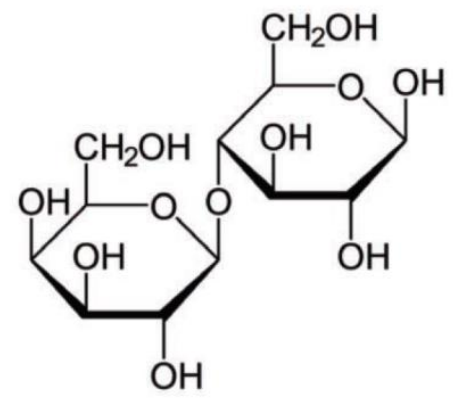

Lactosa: Galactosa- $\beta(1 \rightarrow) \alpha-$ Glucosa

Figura 5. Estructura química de la lactosa

\section{Polisacáridos.}

Son glúcidos producidos por la unión de varias moléculas de monosacáridos, algunos son polímeros de la glucosa, los polisacáridos se diferencian del resto de azúcares porque no cristalizan por no ser dulces y no disolverse en agua ${ }^{11}$. Los polisacáridos más comunes son:

- Almidón: de origen vegetal, está formado por moléculas de D-glucosa unidas por enlaces glucosídicos tipo a 1,4 y 1,6. Se encuentran en hortalizas de tierra como raíces y tubérculos, cereales y granos andinos y leguminosos ${ }^{11}$. 
- Glucógeno: de origen animal y de estructura similar a la del almidón, pero con más ramificaciones después de 12 a 14 residuos de glucosa linear. Se encuentra en carnes y vísceras animales ${ }^{11}$.

- Celulosa: es el componente principal de las paredes de las células vegetales, es un polímero de glucosa ${ }^{11}$.

Los alimentos que tienen gran cantidad de carbohidratos son: almidones, azúcares, fruta, leche y el yogurt. Este tipo de alimentos afecta la glucosa en la sangre mucho más que otros, tales como la carne y los sustitutos de carne, los vegetales o las grasas.

Las fuentes más importantes son: pan, biscochos, panecillos, galletas y tortillas. Frijoles (garbanzos, rojos, habas, pintos, blancos), lentejas y guisantes, cebada, trigo, cuscús, fécula de maíz, kasha, pasta y arroz. Fruta (enlatada, seca, fresca y congelada) y jugo de fruta. Verduras con almidón tales como yuca, maíz, guisantes, plátanos, papas, calabaza de invierno y camotes o batatas. Suero de leche, leche, leche de soya y yogur. Palomitas de maíz, papitas fritas y galletas de arroz. Dulces, tales como caramelos, galletas, tortas y pasteles, donas, helado, helado de yogur, miel, mermelada, jalea, tartas, budines, azúcar y jarabe de maíz ${ }^{12}$.

\section{Química de la lactosa.}

La lactosa está presente en la leche de la mayoría de los mamíferos. El rol más importante de la lactosa en la leche humana es el de proveer energía, la cual lo hace la mitad de la energía que el infante necesita. Es el principal carbohidrato de la leche materna donde constituye el $7 \%$, casi el doble que el de la leche de vaca el cual aporta $4,8 \%{ }^{13}$.

\section{Metabolismo de la lactosa.}

Las disacaridasas enzimas ubicadas en la parte más apical de las células del epitelio intestinal absortivo. Son hidrolasas que catalizan el desdoblamiento de los disacáridos a unidades constituyentes monosocaridos ${ }^{14}$.

Los carbohidratos no absorbidos pueden ser fermentados en el colon por bacterias, conduciendo a la producción de dióxido de carbono, hidrógeno y metano, así como 
los ácidos propiónico y butírico (ácidos grasos de cadena corta). El ácido butírico puede ser utilizado por la mucosa del colon como fuente de energía y el propionato puede ser absorbido y luego eliminado por el hígado?.

La lactasa situada en el lumen de las microvellosidades de la célula epitelial intestinal y que cataliza la hidrólisis de la lactosa ${ }^{14}$.

En el lumen del duodeno y yeyuno habrá una apreciable cantidad de monosacáridos.

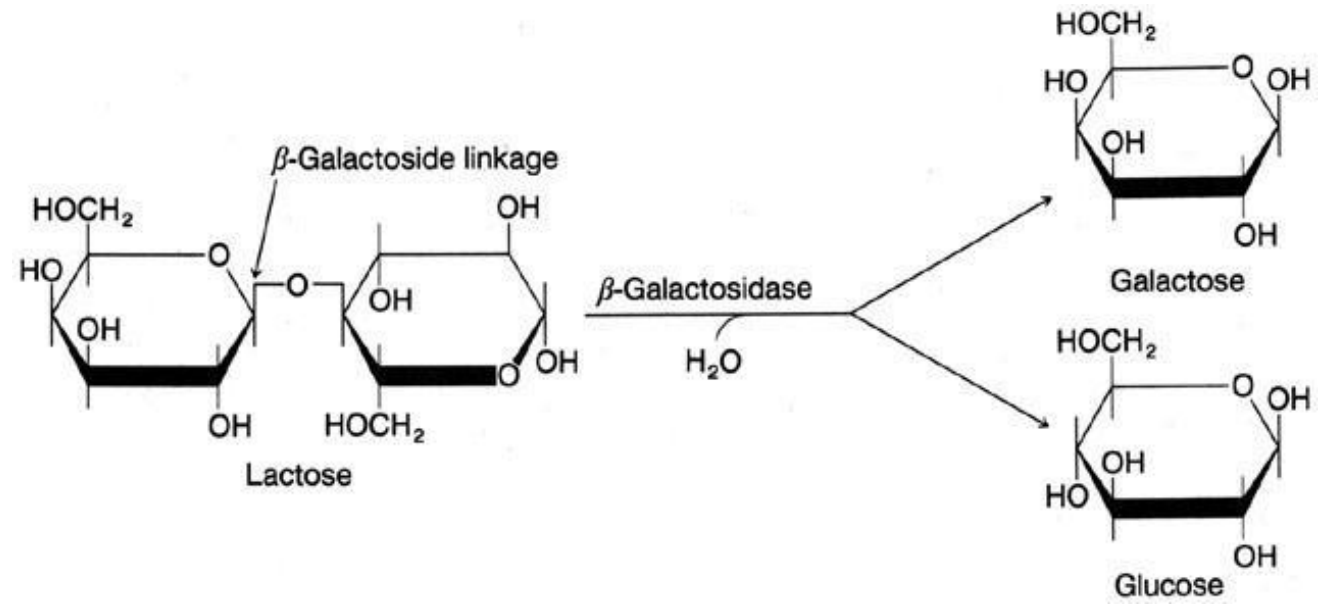

Figura 6. Metabolismo de la lactosa

Figura 3: Metabolismo de la lactosa. Tomado de Composición de la leche y valor nutricional, por Wattiaux, M. A. 2008. Instituto Babcock para la Investigación y Desarrollo Internacional de la Industria Lechera. Universidad de Wisconsin-Madison.

La ingesta de productos lácteos, a lo largo de la evolución del ser humano ha determinado que la actividad de LPH se inicia a partir de las 34 semanas de gestación, y se prolonga a lo largo de su vida?.

\section{Ruta Metabólica de la lactosa.}

La hidrolización de la lactosa en sus monosacáridos, permite que el transportador de glucosa dependiente de sodio (el SGLT) ingrese al interior del enterocito contra un gradiente de concentración, a través de un sistema de transporte activo ${ }^{15}$. Este cotransportador ha sido clonado y secuenciado ${ }^{16}$. Tiene una secuencia de 664 
aminoácidos y no presenta similitud con los transportadores de glucosa (GLUT) mediante difusión facilitada, la familia GLUT ${ }^{17}$. Tiene 12 dominios helicoidales transmembrana con la región aminoterminal en el citoplasma ${ }^{18}$.

La hexosa transportada a través del SGLT1 permite un transporte de sodio en la misma dirección. El mecanismo se basa en la formación de un complejo $\mathrm{Na+-hexosa-}$ transportador en la membrana de borde en cepillo del enterocito provocado por el gradiente de $\mathrm{Na}+$ a ambos lados de la membrana. El $\mathrm{Na}+$, una vez unido al transportador, incrementaría la afinidad de éste por las hexosas y, al separarse el $\mathrm{Na}+$ del transportador, la afinidad por las hexosas unidas disminuiría, abandonando al transportador ya en el interior de la célula ${ }^{19}$. La energía para este transporte activo proviene del gradiente electroquímico de sodio a ambos lados de la membrana de borde en cepillo. Este gradiente de sodio es mantenido por la $3 \mathrm{Na}+/ 2 \mathrm{~K}+-\mathrm{ATPasa}$ de la membrana basolateral, que bombea los iones de sodio co-transportado fuera del enterocito $^{20}$. El resultado es que por cada molécula de glucosa que atraviesa la membrana de borde en cepillo dos iones de sodio ( $\mathrm{y}$ dos aniones) son también transportados a través del epitelio.

La no presencia de SGLT funcional, debido a mutaciones en el gen codificador, es la etiología de la malabsorción de glucosa-galactosa, una enfermedad congénita no frecuente ${ }^{21}$. Las personas que la presentan pueden absorber fructosa e hidrolizar lactosa, sacarosa y maltosa, pero no pueden absorber los monosacáridos glucosa y galactosa liberados ${ }^{22}$. Esta deficiencia genera diarrea grave en neonatos, que puede ser mortal. Al igual que en el caso de la fructosa, el paso de la glucosa y de la galactosa desde el citosol del enterocito al flujo sanguíneo es llevado a cabo por un proceso pasivo a favor del gradiente de concentración de estos azúcares estableciéndose como responsable de esta difusión facilitada al transportador GLUT, situado en la membrana basolateral. Una vez dentro de la célula, la glucosa será fosforilada por la hexoquinasa

para dar glucosa 6-fosfato, el primer paso del glicólisis. La galactosa es el epímero C4 de la glucosa. Sobre la galactosa actúa la galactoquinasa produciendo galactosa 1fosfato, que será el sustrato de la galactosa 1 fosfato uridiltransferasa para dar lugar a glucosa 1-fosfato. La glucosa 1-fosfato producida por esta ruta es convertida en 
glucosa 6-fosfato por la fosfoglucomutasa, entrando de este modo en la ruta glicolítica.

\section{Ruta de Leloir}

Ruta de la tagatosa-6-P

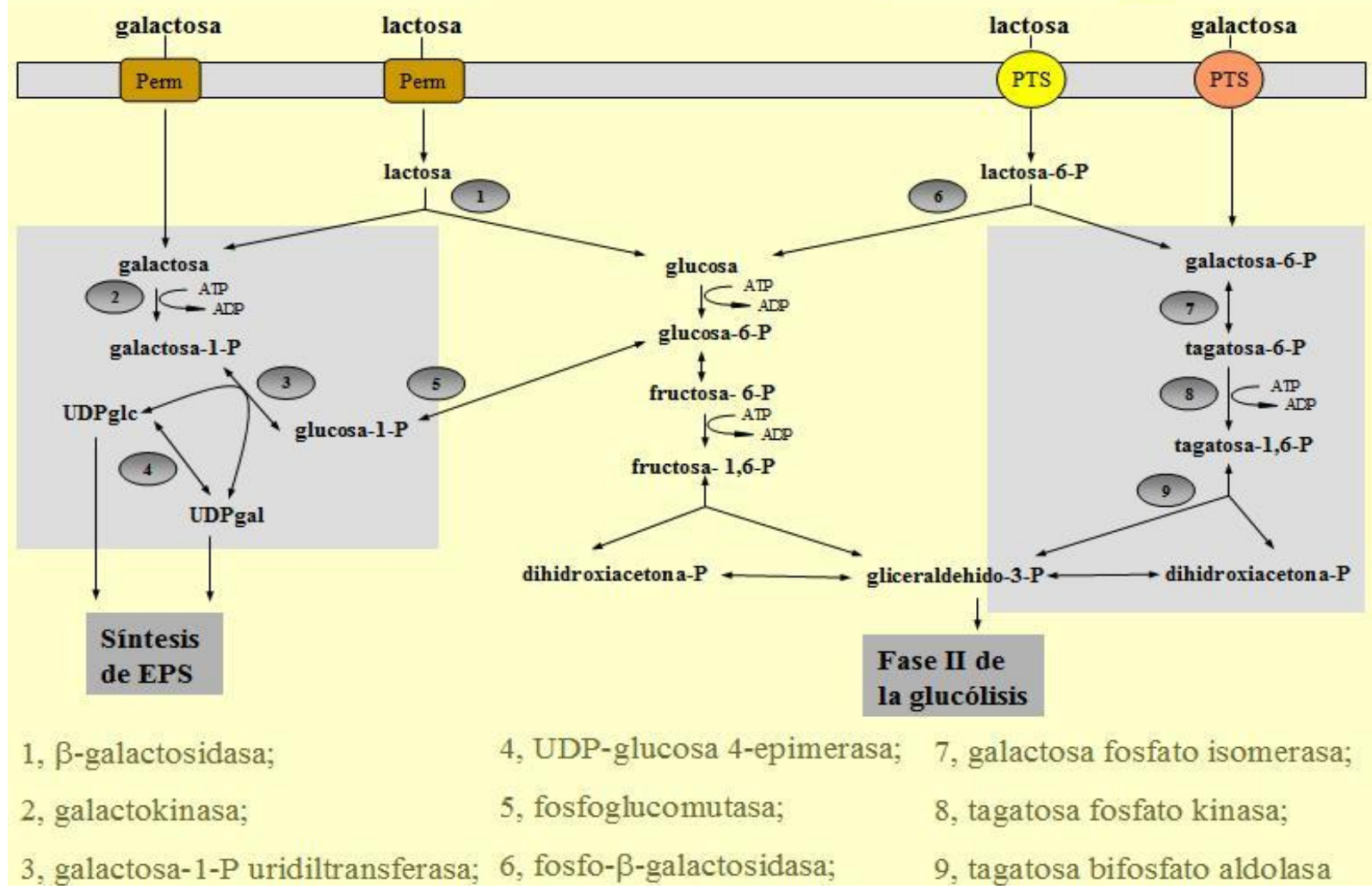

Figura 7. Ruta del metabolismo de la Lactosa.

1, $\beta$-galactosidasa; 2, galactokinasa; 3, galactosa-1-P uridiltransferasa; 4, UDP-glucosa 4-epimerasa; 5, fosfoglucomutasa; 6 , fosfo- $\beta$-galactosidasa; 7 , galactosa fosfato isomerasa; 8 , tagatosa fosfato kinasa; 9 , tagatosa bifosfato aldolasa. En el resto de reacciones intervienen los mismos enzimas que en la vía homofermentativa. EPS, exopolisacáridos.

Fuente: Poolman, B. 1993. Energy transduction in lactic acid bacteria. FEMS Microbiol. Rev. 12:125-148.

\section{La leche.}

Las investigaciones indican que "la leche es una suspensión coloidal de partículas nutritivas, carbohidratos, proteínas, triglicéridos, ácidos grasos, ésteres de fosfóricos de azúcares, grasas, minerales, vitaminas, nucleótidos, bases nitrogenadas, gases, 
compuestos volátiles, dispersas en una fase acuosa y en la fase grasa, con repercusión en la nutrición de sus consumidores ${ }^{23}$.

La leche presenta sustancias como: agua, grasa, proteína, lactosa, vitaminas, minerales; a las cuales se les denomina sólidos totales. Los sólidos totales varían por múltiples factores como: la raza, el tipo de alimentación, el medio ambiente y el estado sanitario de la vaca entre otros ${ }^{24}$.

Tabla 1. Composición general de la leche en diferentes especies

\begin{tabular}{lccc}
\hline Nutriente (g) & Vaca & Búfala & Mujer \\
\hline Agua & 88 & 84 & 87,5 \\
Energía (kcal) & 61 & 97 & 7,0 \\
Proteína & 3,2 & 3,7 & 1,0 \\
Grasa & 3,4 & 6,9 & 4,4 \\
Lactosa & 4,7 & 5,2 & 6,9 \\
Minerales & 0,72 & 0,79 & 0,20 \\
\hline
\end{tabular}

\section{El agua}

El agua es la fase dispersante, en la cual los glóbulos grasos y demás componentes de mayor tamaño se encuentran emulsionados o suspendidos. Las proteínas se encuentran formando un coloide en estado de "sol" liófobo (caseína y globulina) o liófilo (albúmina), la lactosa y las sales se hallan en forma de solución verdadera. El peso específico de la leche está en el rango entre 1,027 y 1,035, con una media de 1,032. El punto de congelación se encuentra por término medio entre $-0,54^{\circ} \mathrm{C}$ y $-0,55^{\circ} \mathrm{C}$ (valores límites: $-0,51^{\circ} \mathrm{C}$ y $-0,59^{\circ} \mathrm{C}$ ) en virtud de la lactosa y sales disueltas; la técnica de su determinación es la crioscopía y ha sido adoptada en el examen de la leche para determinar posibles adulteraciones por adición de agua. Así mismo puede influir sobre el punto de congelación de la leche la acidificación, en cuyo caso el punto crioscópico disminuye. El calentamiento de la leche origina la elevación del punto de congelación ${ }^{25}$.

\section{Proteínas}


La concentración de proteína en la leche es del 3,5\% (fluctuando desde el 2.9\% al $3.9 \%$ ). Esta proteína es una mezcla de fracciones proteicas diferentes y de pesos moleculares distintos. Las proteínas se clasifican en dos grupos: caseínas (80\%) y proteínas séricas $(20 \%)^{24}$.

La caseína es la proteína más abundante, y también se encuentra en otros alimentos, existen tres tipos de caseínas ( $\alpha$, $\beta$ y Kapa caseína), la leche también contiene albúmina y la globulina. El valor biológico de la caseína en la alimentación es debido a su contenido en aminoácidos esenciales que se separan de la parte acuosa por acción de enzimas como la renina o la quimiocina, que son las responsables de la precipitación de la proteína en la elaboración de quesos ${ }^{25}$. El comportamiento de los diferentes tipos de caseína en la leche al ser tratada con calor, diferente $\mathrm{pH}$ (acidez) y diferentes concentraciones de sal, provee las características de los quesos, los productos de leche fermentada y las diferentes formas de leche ${ }^{26}$.

La albúmina está en una concentración de 0.5\%.Las albúminas se desnaturalizan con facilidad al calentarlas. Por esto durante el proceso de calentamiento a altas temperaturas se destruye gran parte de la proteína sérica ${ }^{25}$.

Las globulinas Son las proteínas que más fluctuaciones experimentan en el transcurso de un período de lactación, desde $9 \%$ al 16\% del total de la proteína, que es la tasa que puede alcanzar en el calostro, disminuye hasta ser de sólo unas milésimas de dicho porcentaje en las últimas etapas de la lactancia ${ }^{25}$.

\section{Componente graso}

La grasa láctea se sintetiza en las células secretoras de la glándula mamaria y constituye cerca del $3 \%$ de la leche; se encuentra en forma de partículas emulsionadas o suspendidas en pequeños glóbulos microscópicos, cuyos diámetros pueden variar de 0.1 a 0.22 micrones que se encuentran rodeados de una capa de fosfolípidos que evitan que la grasa se aglutine y pueda separarse de la parte acuosa. La grasa de la leche puede sufrir alteraciones causadas por la acción de la luz, del oxígeno y enzimas (lipasas). Los procesos hidrolíticos oxidativos conducen a la formación de peróxidos, aldehídos, cetonas y ácidos grasos libres, originándose así alteraciones del sabor que se hace sebáceo 0 rancio ${ }^{25}$. 
La concentración de grasa puede variar por factores como la raza y las prácticas de debidas a la alimentación, además, se mantiene constante en los diversos períodos de lactación, tan sólo en el calostro parece disminuir su porcentaje. ${ }^{25}$. La fermentación de lactosa durante la industrialización baja su concentración en muchos productos, especialmente en los yogures y quesos. Así mismo, leche pretratada con lactasa minimiza los problemas digestivos ${ }^{26}$.

\section{Elementos Minerales}

La leche de vaca presenta en su composición sodio, potasio, magnesio, calcio, manganeso, hierro, cobalto, cobre, fósforo, fluoruros, yoduros. Además de contener otros en cantidades vestigiales, como el aluminio, molibdeno y plata. En la membrana de los glóbulos grasos se encuentran en mayor concentración el calcio, cobre, hierro, magnesio, manganeso, fósforo y zinc. Una parte de los metales, como los alcalinos y los halógenos, se encuentran libres en forma de iones en solución. El calcio, se halla en su mayor parte ligado a la caseína. Tan sólo un tercio del calcio y del magnesio se encuentra en disociación iónica. Además de los cloruros y fosfatos, deben mencionarse también los citratos, presentes en una cuantía media de $2,3 \mathrm{~g} /{ }^{25}$.

\section{Vitaminas}

La leche contiene las siguientes vitaminas: A, D, E, K, B1, B2, B6, B12, C, carotenos, nicotinamida, biotina, ácido fólico, su concentración está sujeto a grandes oscilaciones. El calostro posee una gama vitamínica, contiene de 5 a 7 veces más vitamina $C$ y de 3 a 5 veces más vitaminas $B 2, D$ y $E$ que la leche normal. El ciclo del año, tiempo atmosférico, ambiente y la alimentación puede influir en las concentraciones de vitaminas; este último factor repercute especialmente en los carotenos y en la vitamina A como consecuencia de la abundante ingestión de carotenos cuando la base de la alimentación son forrajes frescos. La vitamina $E$ es 10\% más abundante en épocas en que el ganado tiene acceso a forraje más toscos, lo cual dependa del mayor contenido graso de la leche en verano. La concentración de las vitaminas hidrosolubles se conserva constantemente. En la vitamina C se observan fluctuaciones dependiendo de la alimentación. Son variadas las influencias de la manipulación de la leche sobre su 
contenido vitamínico ya que en el almacenamiento se producen pérdidas de vitaminas, dependientes de las radiaciones lumínicas y de la temperatura ${ }^{25}$.

\section{Enzimas}

Las enzimas influyen de varias maneras en la calidad de la leche y en el origen de distintas alteraciones. Las enzimas de la leche carecen de valor desde el punto de vista alimenticio, sobre todo para los organismos ya desarrollados ${ }^{27}$.

Las enzimas lácteas tienen dos orígenes: las corporales y las enzimáticas. Las primeras llegan directamente a la leche en la que se encuentran en forma libreprocedentes de la sangre, o bien de las células corporales. Sin embargo pueden llegar a la leche con las células. En ambos casos se trata de enzimas originadas en el organismo. Las segundas se originan en la leche misma, producto de la acción de los gérmenes ${ }^{25,27}$.

Las enzimas forman dos grupos: hidrolasas cuyo mecanismo de acción se caracteriza por un desdoblamiento hidrolítico, a este grupo pertenecen entre otras, las esterasas, lipasas, carbohidratasas y proteasas. Entre las esterasas es importante la lipasa que actúa cuando la leche es depositada sin refrigeración, dándole un sabor rancio. Las lipasas se inactivan a temperaturas superiores a los $60^{\circ} \mathrm{C}$, por lo tanto, no son evidenciables después de la pasteurización. A las esterasas pertenecen las fosfatasas que se clasifican en ácidas y alcalinas, la fosfatasa alcalina se encuentra en la membrana proteica de los glóbulos grasos y es inactivada al someter la leche a procesos de calentamiento $62^{\circ} \mathrm{C}$ durante 30 minutos o a $72^{\circ} \mathrm{C} 15$ segundos ${ }^{25}$. El otro grupo importante de enzimas son las oxido-reductasas, siendo las más importantes son la catalasa y la peroxidasa que sirven como indicadoras de la calidad microbiológica de la leche ${ }^{25}$.

\section{Intolerancia a la lactosa.}

Intolerancia a la lactosa (LI) es una condición gastrointestinal común que se debe a la incapacidad para digerir y absorber lactosa de la dieta. La lactosa requiere hidrólisis por la enzima lactasa en D-glucosa y D-galactosa antes de que pueda 
ser absorbida. Alrededor del $70 \%$ de la población mundial sufre de LI debido a una disminución gradual programada genéticamente en la expresión de lactasa después del destete, llamada no persistencia de la lactasa (LNP) ${ }^{28},{ }^{29}$. La introducción de la producción lechera y el consumo regular de leche de vaca hace más de 5000 años seleccionaron individuos que toleraban los alimentos que contienen lactosa más allá de la primera infancia ${ }^{30}$. La genómica poblacional sugiere que la capacidad de digerir lactosa más allá de la infancia (es decir, la persistencia de la lactasa) surgió alrededor de la época de la Edad de Bronce Euroasiática (3000-1000 a. C.) ${ }^{31}$. Si bien es probable que la ingesta regular de leche y productos de leche fermentada mejore el estado nutricional de las personas, no está claro si otros beneficios clínicos han promovido la selección genética de la persistencia de la lactasa ${ }^{28}$.

LI presenta síntomas gastrointestinales de leves a moderados, que incluyen dolor abdominal, flatulencia y diarrea. Los niños menores de 5 años generalmente pueden tolerar la lactosa ya que la LI primaria raramente se manifiesta clínicamente en este grupo de edad ${ }^{32}$, 33. En un estudio sobre pruebas de hidrógeno en aliento para intolerancia a la lactosa, Tras la ingesta de $25 \mathrm{~g}$ de lactosa, 14 pacientes presentaron flatulencia (60,87\%), 9 distensión (39,13\%), 7 dolor abdominal $(30,43 \%) 6$ cólicos $(26,09 \%)$ y 3 diarrea (13,04\%). El síntoma más sensible fue la flatulencia (80\%) y la diarrea el síntoma más específico $(84,61 \%)$. Con la positividad de la prueba siendo del $43,47 \%$, el síntoma con valor predictivo positivo (VPP) más alto fueron la flatulencia y dolor abdominal (ambos con $57,14 \%$ ) y el síntoma con valor predictivo negativo (VPN) más alto también fue la flatulencia $(77,78 \%)$. De igual manera, la flatulencia y el dolor abdominal tuvieron el mayor coeficiente de probabilidad positivo (CPP), siendo ambos 1,73. La diarrea resultó con el coeficiente de probabilidad negativo (CPN) más alto $(1,06)^{34}$. Si bien la malabsorción transitoria de lactosa después de la gastroenteritis es relativamente común en niños menores de 2 años ${ }^{35},{ }^{36}$, los síntomas más persistentes debido a la enteropatía por leche de vaca a menudo no se reconocen ${ }^{37}$ y pueden tratarse de manera inapropiada con proteínas de leche de vaca sin lactosa, que contiene la fórmula ${ }^{38}$.

Fisiología de la absorción de lactosa 
Lactosa ( $\beta$-galactosil-1,4 glucosa) es el carbohidrato principal en la leche humana y de mamíferos. La leche humana contiene aproximadamente $7,5 \mathrm{~g} / 100 \mathrm{ml}$ de lactosa, en comparación con aproximadamente $5 \mathrm{~g} / 100 \mathrm{ml}$ en leche de vaca y otra leche de mamífero ${ }^{40}$. Un niño a término puede digerir $60-70 \mathrm{~g}$ de lactosa por día, equivalente a un litro de leche materna. Los bebés pequeños no absorben toda la lactosa ingerida de la leche materna (malabsorción de lactosa fisiológica). La lactosa mal absorbente se fermenta en el colon a ácidos grasos de cadena corta (SCFA), hidrógeno (H2), dióxido de carbono (CO2) y metano (CH4). La lactosa mal absorbida también se convierte en ácido láctico por bacterias entéricas (Streptococcus lactis y otros) ${ }^{40}$.

\section{Fisiopatología de la malabsorción de lactosa}

Las personas con $\mathrm{LI}$ absorben entre el 42 y el $77 \%$ de la lactosa ingerida después de una dosis de $12,5 \mathrm{~g}$, en comparación con el $95 \%$ en persistentes de lactasa ${ }^{41}$. Las manifestaciones clínicas de LI se deben a cambios de fluido osmótico en el intestino, así como a la formación de gas y la distensión intestinal. Esto puede presentarse con dolor abdominal, flatulencia y diarrea. Varios factores influyen en si la lactosa mal absorbida causará síntomas gastrointestinales, incluyendo la dosis, la matriz de alimentos, el tiempo de tránsito intestinal y la capacidad de fermentación de la microbiota fecal. En individuos con LI, la ingestión continua de lactosa puede mejorar la diarrea y la flatulencia debido a la proliferación de bacterias que no fermentan la fermentación de lactosa (por ejemplo, Bifidobacteria). La diarrea por LI ocurre principalmente en lactantes y niños pequeños ya que este grupo de edad no tiene la capacidad de compensar por reabsorción colónica. En niños mayores, la reabsorción de productos de fermentación (por ejemplo, SCFA, lactato) reduce la carga osmótica y reduce significativamente la diarrea.

\section{Genética y epidemiología de la intolerancia a la lactosa}

El gen de la lactasa se encuentra en el brazo largo del cromosoma 2 (región $2 \mathrm{q} 21)^{42}$. Su expresión está regulada por una región promotora localizada aguas arriba del gen. La máxima expresión de lactasa en enterocitos ocurre durante los primeros meses de vida y disminuye después del destete ${ }^{43,44}$. 
Varios polimorfismos de un solo nucleótido (SNP) se han identificado en la región promotora del gen de la lactasa ${ }^{45}$. El polimorfismo más común asociado con la persistencia de la lactasa en caucásicos se caracteriza por un cambio de $\mathrm{C}>\mathrm{T}$ en 13910 pares de bases aguas arriba del gen de la lactasa. Varios otros polimorfismos para la persistencia de lactosa se han identificado con diferencias regionales específicas ${ }^{46-51}$. Mientras que el genotipo C / C13910 se asocia con malabsorción de lactosa, los genotipos C / T y T / T se encuentran en individuos con persistencia de lactasa ${ }^{29}$. Los heterocigotos portadores del alelo $\mathrm{C} / \mathrm{T}$ difieren en su respuesta a una carga de lactosa oral, en comparación con los genotipos $\mathrm{C} /$ C y $T$ / $T$, lo que sugiere un fenotipo intermedio ${ }^{52}$.

La persistencia de la lactasa es común en personas del norte de Europa, África Occidental o Medio Oriente. Las cifras de prevalencia estimadas para LI primario debido a LNP son de $2-5 \%$ en el norte de Europa (Escandinavia, Alemania, Gran Bretaña), $17 \%$ en Finlandia y el norte de Francia, aproximadamente $50 \%$ en Sudamérica y África, y entre 90 y $100 \%$ en Sudeste de Asia ${ }^{51}$. En adultos norteamericanos, las tasas de LI varían según la etnia (79\% de los indígenas americanos, $75 \%$ de los afroamericanos, $51 \%$ de los hispanos y $21 \%$ de los caucásicos) ${ }^{33,54}$.

\section{Definiciones y clasificaciones}

Es importante distinguir entre los términos deficiencia de lactasa, malabsorción de lactosa y la LI que a menudo se usan indistintamente. La "deficiencia de lactasa" describe el estado de expresión de lactasa reducida, en comparación con los recién nacidos a término. La "malabsorción de lactosa" indica que no toda la lactosa ingerida se absorbió y que una parte ha llegado al intestino grueso. La "LI" se define clínicamente como malabsorción de lactosa con síntomas gastrointestinales asociados. Existen cuatro tipos clínicos principales de LI: deficiencia de lactasa en el desarrollo, deficiencia congénita de lactasa (alactasia), insensibilidad a la lactasa (LNP) e intolerancia secundaria a la lactosa.

\section{Deficiencia de lactasa del desarrollo}

La lactasa es la última disacaridasa del intestino delgado que se desarrolla durante el desarrollo intrauterino. En los bebés prematuros (26-34 semanas de gestación), 
la actividad de la lactasa alcanza aproximadamente el 30\% de la de los recién nacidos a término (retraso de la maduración) ${ }^{43}$. Al comenzar la leche materna o la fórmula, los bebés prematuros pueden desarrollar signos clínicos de malabsorción de lactosa cuando se exponen a la leche materna o a la fórmula, que generalmente son transitorios. Una revisión Cochrane que examinó el papel de la administración de suplementos de lactasa enteral en las mediciones antropométricas y los síntomas gastrointestinales en recién nacidos prematuros no encontró beneficios clínicos importantes ${ }^{55,56}$.

LNP (también llamada hipolactasia) es la causa más común de intolerancia. Si bien el descenso en los niveles de lactasa comienza poco después del destete, los síntomas generalmente no se manifiestan antes de los 5 años de edad ${ }^{57}$. En un estudio realizado en Indonesia, la prevalencia de hipolactasia sintomática a los 3 años de edad fue del 9,1\%. La prevalencia aumentó a $28.6 \%$ a los 5 años, y $73 \%$ a los $12-14$ años de edad ${ }^{58}$.

\section{Intolerancia a la lactosa secundaria}

La LI secundaria ocurre como resultado del daño de las vellosidades del intestino delgado y la disminución de la expresión de lactasa. En niños pequeños, las causas más comunes de LI secundarias incluyen gastroenteritis viral ${ }^{35}$, giardiasis ${ }^{59}$, enteropatía no relacionada con $\lg E$ de leche de vaca ${ }^{60}$, enfermedad celíaca ${ }^{61}$ y enfermedad de Crohn ${ }^{62}$. La LI secundaria generalmente se resuelve en 1-2 meses, dependiendo del trastorno intestinal subyacente ${ }^{63}$.

\section{Presentación clínica}

La presentación clínica de LI difiere significativamente entre lactantes y niños mayores. Los síntomas generalmente ocurren dentro de los 30-60 minutos de ingerir alimentos que contienen lactosa. Los bebés con malabsorción de lactosa son más propensos a desarrollar diarrea, en comparación con niños mayores y adultos. Un pH fecal bajo $<5.5$ puede causar irritación y excoriación de la piel perianal. Mientras que algunos bebés con LI secundaria pueden experimentar dolor abdominal y distensión, el cólico infantil generalmente no es causado por LI. Por lo tanto, se considera que la fórmula libre de lactosa es ineficaz y no se recomienda para el tratamiento del cólico ${ }^{64}$. 
En niños mayores y adultos, los síntomas de in tolerancia a la lactosa incluyen dolor abdominal, hinchazón, distensión abdominal, flatulencia, borborigmos y diarrea de bajo grado. En una serie de casos de 98 adolescentes indonesios con intolerancia a lactosa, el dolor abdominal fue la principal queja (64.1\%), seguida de distensión abdominal (22.6\%), náuseas (15.1\%), flatulencia $(5.7 \%)$ y diarrea $(1.9 \%)^{58}$. En adolescentes y adultos, los síntomas parecidos al síndrome del intestino irritable se perciben a menudo por LI. Sin embargo, posteriores desafíos doble ciego no han podido demostrar un claro beneficio de la restricción de lactosa en estos pacientes ${ }^{65}$. Por lo tanto, se cree que LI es un factor que contribuye al síndrome del intestino irritable, pero la hiperalgesia visceral y las reacciones a otros carbohidratos fermentables también pueden ser importantes ${ }^{66}$.

\section{Diagnóstico de laboratorio}

El diagnóstico de LI se basa en la observación de síntomas gastrointestinales luego de consumir alimentos que contienen lactosa, incluida la leche materna, la leche de vaca u otra leche de mamífero. Varios métodos de diagnóstico están disponibles para confirmar la malabsorción de lactosa. En los niños, las causas de la LI secundaria siempre deben considerarse en el diagnóstico diferencial.

\section{Pruebas de hidrógeno con aliento lactosa}

La prueba de $\mathrm{H} 2$ en aliento (PHA) es una alternativa sencilla y práctica, no invasiva, de costo accesible y con aceptable confiabilidad diagnóstica es necesaria hacerla para la malabsorción de carbohidratos (ej. lactosa y fructosa) y el sobrecrecimiento bacteriano intestinal (SCBI) que son entidades clínicas frecuentes que causan malabsorción de macro y micronutrientes, con consecuentes deficiencias nutricionales, así como signos y síntomas como meteorismo, borborismos, dolor abdominal, flatulencia y diarrea ${ }^{67 .}{ }^{34}$. La prueba se basa en el principio fisiológico de que las bacterias intestinales producen hidrógeno gaseoso debido a que fermentan carbohidratos. En el intestino, las bacterias hacen esto en mayor medida cuando los carbohidratos de la dieta permanecen sin absorberse; parte de este gas es expulsado como flatulencia o forma parte de otras moléculas, como sulfuros, acetato y ácidos grasos de cadena corta. Sin embargo, la mayor parte del gas se absorbe a través de la pared intestinal, viaja en el torrente sanguíneo y es expulsado a través del intercambio 
alveolar en el pulmón. La única fuente de hidrógeno gaseoso en el aliento es el producido por la flora bacteriana intestinal. Así, una flora bacteriana anormal o incrementada en cantidad y una incapacidad por parte del aparato gastrointestinal para transportar o procesar adecuadamente los carbohidratos provocarán que la cantidad de este gas espirado aumente ${ }^{67,68}$.

Esto puede ser medido fácilmente al tomar una muestra de aliento y midiendo las partes por millón de hidrógeno (ppmh) con un aparato especializado ${ }^{68}$, Las pruebas se realizan utilizando el monitor de hidrógeno en aliento MicroH2 (Micro Medical Limited) y el software HYDRA para graficar resultados. Las pruebas se realizan con $25 \mathrm{~g}$ de lactosa, fructosa o lactulosa disuelta en $100 \mathrm{~mL}$ de agua. Para pacientes pediátricos se calcula la dosis de $1 \mathrm{~g} / \mathrm{kg}$ del carbohidrato de interés, sin exceder la dosis de $25 \mathrm{~g}$ en total. La prueba se toma como positiva cuando las ppmh alcanzaron $\geq 20$ ppm sobre el valor basal, esta prueba es realizada por el gastroenterólogo con experticia para esta prueba ${ }^{69,70}$. Por esta razón, se requiere una prueba de control positivo con lactulosa (un disacárido sintético no absorbible) para la validación de un resultado negativo para la lactosa. Otro método para reducir el riesgo de resultados falsos negativos es la co-medición del metano exhalado ${ }^{71,72}$. Tanto el hidrógeno como el metano son productos de degradación bacteriana de la lactosa. Los niveles de metano exhalado aumentan después de la fermentación bacteriana de la lactosa malabsorbente, incluso si no hay bacterias productoras de hidrógeno. Un aumento en el metano exhalado en $\geq 10$ ppm desde el inicio se considera evidencia de malabsorción de lactosa ${ }^{70}$. La correlación de los resultados de la prueba de hidrógeno en aliento $(\mathrm{BHT})$ con los síntomas clínicos es variable. Mientras que la diarrea de bajo grado y la flatulencia durante la BHT son síntomas muy específicos, el dolor abdominal por sí solo no debe atribuirse a la $\mathrm{LI}^{73}$.

\section{Disacaridasas duodenales}

Lactasa y otras disacaridasas duodenales (sacarasa, maltasa, isomaltasa) se miden en biopsias duodenales que se pueden obtener durante la gastroscopia. En los casos de enteropatía por leche de vaca o enfermedad celíaca con daño velloso, las concentraciones de lactasa se reducen normalmente, mientras que los niveles de sacarasa son suficientes ${ }^{61,74}$. En lactantes con alactasia congénita, la 
lactasa es muy baja o está completamente ausente, mientras que el aspecto histológico del duodeno es normal ${ }^{75}$.

\section{Diagnóstico genético de hipolactasia}

Las pruebas genéticas permiten la predicción de hipolactasia, incluso antes de que los síntomas estén presentes. Los ensayos comerciales se basan en el polimorfismo C> T13910 que se asocia con la persistencia de lactasa en caucásicos. Las pruebas para otros SNP también pueden estar disponibles. La utilidad clínica de esta prueba es controvertida, ya que puede conducir a una restricción innecesaria de lactosa antes de que los síntomas estén presentes.

\section{Tratamiento de la intolerancia a la lactosa}

En bebés con $\mathrm{LI}$, se debe continuar amamantando. En los lactantes alimentados con fórmula, puede estar indicada una prueba limitada de fórmula sin lactosa, $p$. después de gastroenteritis viral. En niños con diarrea persistente después de gastroenteritis aguda, se ha demostrado que la restricción de lactosa acorta la duración de los síntomas gastrointestinales ${ }^{36}$. Se debe intentar reintroducir fórmula o alimentos que contengan lactosa después de 2-4 semanas, según lo tolere. En los bebés con enfermedad celíaca u otra patología del intestino delgado, puede ser necesaria la restricción de lactosa hasta que la afección subyacente se haya resuelto o se haya tratado adecuadamente.

En individuos con LI, los alimentos que contienen lactosa deben reducirse, pero no es necesario eliminarlos por completo. Los adolescentes y adultos con hipolactasia toleran hasta 12-24 g de lactosa al día, si se toman en cantidades divididas. consumo de leche con una comida y en dosis divididas mejora la tolerancia general, ya que ralentiza la liberación de lactosa en el intestino delgado. La lactosa dietética se deriva principalmente de la leche de vaca fresca y otros productos lácteos a base de leche (por ejemplo, yogur, helado). El contenido en yogur es más bajo que en la leche debido a la descomposición de la lactosa por bacterias fermentadoras de lactosa. Como la lactosa se encuentra principalmente en la porción acuosa de la leche, el queso duro solo contiene pequeñas cantidades $(0.1$ a $0.9 \mathrm{~g}$ en $30 \mathrm{~g}$ de queso duro), y el contenido de lactosa de la mantequilla es 
insignificante ${ }^{76}$. Algunos medicamentos contienen lactosa como portador, pero las cantidades raramente son suficientes para ser clínicamente relevantes ${ }^{77}$.

\section{Suplementación de lactasa}

En niños y adultos con $\mathrm{LI}$, se ha demostrado que los suplementos orales de lactasa mejoran la gravedad de los síntomas gastrointestinales después de una exposición a la lactosa ${ }^{78,79}$. La lactasa ingerida se descompone fácilmente por el ácido gástrico y se inactiva. Por lo tanto, el tratamiento con lactasa en recién nacidos solo es efectivo si se agrega a leche materna o fórmula expresada durante varias horas antes de la alimentación ${ }^{80}$.

\section{Papel de la fórmula ampliamente hidrolizada con lactosa en bebés con CMA}

La fórmula ampliamente hidrolizada (EHF), el tratamiento de primera línea para lactantes alimentados con fórmula con CMA, se diseñó inicialmente para tratar la malabsorción. Por esta razón, las EHF de la generación temprana eran típicamente fórmulas basadas en péptidos cortas sin lactosa y con un alto contenido de triglicéridos de cadena media (MCT). En los últimos años, se ha agregado lactosa a la fórmula ampliamente hidrolizada (EHF). Se ha demostrado que la lactosa en fórmula hidrolizada aumenta la absorción de calcio, en comparación con la fórmula libre de lactosa ${ }^{81}$. Los lactantes que padecen de alergia a la leche de vaca toleran la lactosa altamente purificada ${ }^{82,83}$. La restricción de lactosa solo se justifica en lactantes con CMA si existe una enteropatía con deficiencia secundaria de lactasa. La lactosa puede reintroducirse con cautela después de aproximadamente 1 a 2 meses, una vez que los síntomas se hayan resuelto y se haya restablecido la actividad de la lactasa en el intestino delgado. 


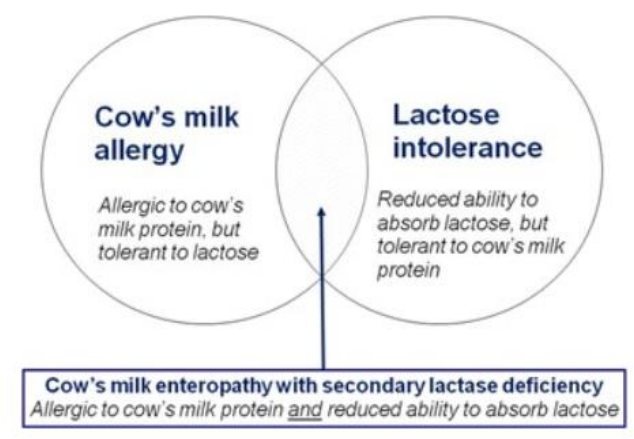

Clinical overlap between cow's milk allergy and lactose intolerance

Figura 8. Superposición clínica entre la alergia a la leche de vaca y la intolerancia a la lactosa.

\section{Adecuación nutricional de las dietas sin lactosa}

En la última década, ha habido una fuerte disminución en el consumo de leche de vaca fresca y un mayor consumo de leche sin lactosa y leches de cereales en la comunidad $^{84}$. Los padres pueden restringir los productos lácteos en sus hijos debido a preocupaciones infundadas sobre la LI o CMA. Un estudio de niños y adolescentes suecos evaluó la probabilidad de evitar la leche de acuerdo con el estado genético persistencia de lactasa ${ }^{85}$. Mientras que la $\mathrm{LI}$ en adolescentes no afectó los niveles de vitamina $D$ ni las variables antropométricas, se asoció con una ingesta reducida de leche y calcio, en comparación con aquellos que toleraron la lactosa (OR 3,2; IC del 95\%: 1,5; 7,3)

Los principales efectos adversos para la salud de LI ocurren como resultado de la evitación de la leche y la ingesta reducida de calcio. Evitar los productos lácteos puede provocar raquitismo nutricional en los niños pequeños ${ }^{86}$, así como una baja densidad mineral ósea y un mayor riesgo de fractura más adelante en la vida ${ }^{87}$. El consumo de calcio es un marcador de la adecuación dietética y se correlaciona estrechamente con la ingesta de otros micronutrientes ${ }^{88}$. La absorción de calcio en individuos con $\mathrm{LI}$ es normal, lo que significa que el calcio puede administrarse como un suplemento oral en formatos no lácteos ${ }^{89}$.

\subsection{Objetivos e hipótesis}

\section{Objetivos.}

Objetivo general. 
Evaluar si existen diferencias de los síntomas y signos característicos de la $\mathrm{LI}$ en los pacientes de 16 a 30 años de los grupos al que se le administra leche deslactosada y al que se le administra leche sin lactosa en el Hospital Hipólito Unanue en el 2015.

\section{Objetivos específicos.}

- Determinar la frecuencia de los síntomas y signos característicos de la intolerancia a la lactosa en los pacientes de 16 a 30 años en el grupo al que se le administra leche deslactosada en el Hospital Hipólito Unanue en el 2015.

- Discriminar los síntomas y signos característicos de la intolerancia a la lactosa en los pacientes de 16 a 30 años en el grupo al que se le administra leche sin lactosa en el Hospital Hipólito Unanue en el 2015.

- Conocer las características sociodemográficas de los pacientes de 16 a 30 años en los grupos de intervención y de control en el Hospital Hipólito Unanue en el 2015.

\section{Hipótesis.}

\section{Hipótesis general.}

- H1: La diferencia de los síntomas característicos de la intolerancia a la lactosa en los pacientes del grupo al que se le administró leche deslactosada al $15 \%$ y el grupo al que se le administró leche sin lactosa es inferior al 10\%.

- H0: La diferencia de los síntomas característicos de la intolerancia a la lactosa en los pacientes del grupo al que se le administró leche deslactosada y el grupo al que se le administró leche sin lactosa es superior o igual al $10 \%$

\section{CAPİTULO II}

\section{MÈTODO}

\subsection{Tipo y diseño de investigación}

Tipo de investigación.

El tipo de investigación es cuantitativa.

\section{Diseño de investigación.}


- Según el objetivo: El estudio es de tipo analítico ya que se estableció una relación causa efecto mediante una intervención con leche deslactosada y observar los efectos en los síntomas de intolerancia a la lactosa.

- Según el control de la variable independiente: El estudio experimental cuyo diseño fue de un ensayo clínico aleatorizado de equivalencia, cuya intervención fue (leche deslactosada conteniendo 15\% de lactosa) para observar su efecto sobre una variable de respuesta.

- Según el número de mediciones: El estudio es longitudinal porque la variable de respuesta se evaluó después de la intervención.

- Según la direccionalidad: El estudio es prospectivo ya que los datos utilizados ocurrieron después del inicio del estudio.

\title{
Diagrama del diseño Cuasi-experimental.
}

\author{
GE1 (R) $\quad \mathrm{X} \quad \mathrm{OE}_{1}$ \\ $\mathrm{GC1}\left(\mathrm{)}-\mathrm{OC}_{1}\right.$
}

GE1: Individuos con intolerancia a la lactosa que recibirán "leche deslactosada" en un $15 \%$.

GC1: Individuos con intolerancia a la lactosa que recibieron leche sin lactosa.

R: Se consideró aleatoriedad

$X$ : Individuos que recibieron leche deslactosada

$\mathrm{OE}_{1}$ : Nivel de síntomas de intolerancia a la lactosa del grupo de leche deslactosada $\mathrm{OC}_{1}$ : Nivel de síntomas de intolerancia a la lactosa del grupo control de leche sin lactosa

\subsection{Variables}


Variables de estudio:

- Variable Independiente:

Variable de intervención: leche deslactosada conteniendo 15\% de lactosa.

Variable control: leche sin lactosa.

- Variable Dependiente:

Síntomas y signos de intolerancia a la lactosa

- Variable interviniente: Edad 
Tabla 2. Operacionalización de variables.

\begin{tabular}{|c|c|c|c|c|}
\hline & Tipo de variable & Definición conceptual & Escala de medición & Indicadores \\
\hline Edad & Cuantitativa discreta & & Razòn & Número de años \\
\hline $\begin{array}{l}\text { Consumo de leche } \\
\text { deslactosada al } 85 \%\end{array}$ & Cualitativa & $\begin{array}{l}\text { Leche conteniendo } 15 \% \text { de } \\
\text { lactosa*, por un proceso } \\
\text { mecánico. } \\
\text { *A comparación de una } \\
\text { leche entera. }\end{array}$ & Ordinal & $\begin{array}{l}\text { 1.No presenta ningún síntoma de } \\
\text { intolerancia a la lactosa } \\
\text { 2. Presenta un síntoma de } \\
\text { intolerancia a la lactosa. } \\
\text { 3. Presenta más de dos síntomas de } \\
\text { intolerancia a la lactosa. }\end{array}$ \\
\hline $\begin{array}{l}\text { Consumo de leche } \\
\text { sin lactosa }\end{array}$ & Cualitativa & $\begin{array}{l}\text { Leche que se le ha reducido } \\
\text { el } 99,9 \% \text { de lactosa, por un } \\
\text { proceso enzimático. }\end{array}$ & Ordinal & $\begin{array}{l}\text { 1. No presenta ningún síntoma de } \\
\text { intolerancia a la lactosa } \\
\text { 2. Presenta un síntoma de } \\
\text { intolerancia a la lactosa. } \\
\text { 3.Presenta más de dos síntomas de } \\
\text { intolerancia a la lactosa }\end{array}$ \\
\hline
\end{tabular}

Fuente: Elaboración Propia. 


\subsection{Población y Muestra}

Población objetivo.

Jóvenes adultos de 16 a 30 años intolerantes a la lactosa de la ciudad de Lima.

Población en estudio.

Pacientes jóvenes adultos de 16 a 30 años que han sido diagnosticados como intolerantes a la lactosa y que asisten al consultorio externo de Gastroenterología del Hospital Hipólito Unanue.

\subsection{Criterios de Selección}

\section{Criterio de inclusión.}

- Adultos jóvenes de 16 a 30 años, pacientes del consultorio externo de gastroenterología diagnosticados como intolerantes a la lactosa y que han firmado el consentimiento informado.

- Adultos jóvenes de 16 a 30 años de uno u otro sexo

\section{Criterio de exclusión.}

- Adultos jóvenes pacientes del consultorio externo de gastroenterología que no presenten intolerancia a la lactosa y los que no hayan firmado el consentimiento informado.

- Adultos jóvenes gestantes o lactantes.

- Adultos jóvenes con antecedentes de enfermedad gastroenterológica.

- Adultos jóvenes con alteraciones psicológicas

\section{Tamaño muestral.}

Cálculo de tamaño de muestra para estudio de equivalencia:

$P=0,9$

$A L F A=0,05$

$\mathrm{BETA}=0.80$

$D-d=0,15$

Tamaño de muestra 50 pacientes 
50 adultos jóvenes que cumplen con los criterios de inclusión y que asisten periódicamente al consultorio de gastroenterología.

- El $50 \%$ de la muestra (25 pacientes con intolerancia a la lactosa) recibieron "leche deslactosada" (Grupo Experimental).

- El otro $50 \%$ de la muestra (25 pacientes con intolerancia a la lactosa) recibieron "leche sin lactosa" (Grupo Control).

Muestreo. El método seleccionado para la recolección de datos fue no probabilístico por

conveniencia. 


\subsection{Instrumento de investigación}

Para la obtención de la información se utilizó cuestionarios validados por expertos y sometidos a una prueba piloto.

\subsection{Validación de cuestionarios con expertos.}

Cada cuestionario fue validado por 5 expertos en intolerancia a la lactosa, a los cuales se les indicó el objetivo principal de la investigación y se les entregó el cuadro de Operacionalización de las variables. Una vez que el experto estuvo familiarizado con la investigación se le entregó el cuestionario y se le indicó colocar una puntuación del 1 al 5 (siendo 1 el nada relevante y 5 el muy relevante) a cada pregunta del cuestionario tomando como base la relevancia, coherencia y claridad de cada pregunta. Para contrastar la validez de los ítems se preguntó a los expertos se realizó una evaluación cualitativa y cuantitativa mediante la prueba binomial en excell.

Se estableció la siguiente hipótesis:

Ho: La proporción de los jueces que dicen "Si" es igual a la de los jueces que dicen "No". Es decir entre los jueces no hay concordancia. La probabilidad de éxito es de $50 \%$.

Ha: La proporción de los jueces es diferente de 0.5. Si hay concordancia entre los jueces. (Se adjunta en anexos la evaluación cuantitativa)

Prueba Piloto.

Para determinar si el cuestionario era comprendido por las personas a ser encuestadas se realizó una encuesta piloto a 10 personas diagnosticadas con intolerancia a la lactosa atendidas en el consultorio externo de gastroenterología del Hospital Hipólito Unanue. De esta forma se llevaron a cabo algunos ajustes a la encuesta original.

\subsection{Técnicas y procedimientos de recolección}

Las encuestas validadas se aplicaron a la muestra del estudio de la siguiente forma:

- Los participantes del estudio que asistieron al consultorio de gastroenterología del Hospital Nacional Hipólito Unanue fueron informados 
acerca del estudio y la prueba de las leches, aquellos que aceptaron firmaron el consentimiento informado.

- Luego se les aplicó el cuestionario $N^{\circ} 1$ de Consumo de lácteos a fin de determinar si consumen leche, el tipo y/o las causa por las cuales no lo consume.

- De forma aleatoria se les brindó un vaso de leche (al 50\% de la muestra un vaso de "leche sin lactosa" y al otro $50 \%$ "leche deslactosada") sin que el participante supiera que tipo de leche se le estaba brindando, durante los siguientes 15 días, así mismo el investigador no sabía qué tipo de leche asignaba a los participantes. Al inicio (los 3 primeros días) la administración de la leche se realizó fuera del consultorio de gastroenterología, luego se les enseño la forma de preparación de cada leche y se les entregó el producto para que puedan consumirlo en casa.

- Pasada 2 horas de cada ingesta se les realizó la encuesta №2 para ver la tolerancia y los síntomas presentados al tomar la leche ofrecida.

- Para el resto del día se permitió a los participantes comer libremente, un nutricionista les indicó que escogieran alimentos libres de lactosa y evitaran los alimentos que a menudo producen síntomas gastrointestinales como menestras, cantidades excesivas de cebollas, col, manzanas, café y alcohol entre otros.

- La recolección de datos se realizó fuera del consultorio externo de gastroenterología del Hospital Nacional Hipólito Unanue durante un mes (periodo en el que se completó la muestra del estudio).

\subsection{ANÀLISIS DE DATOS}

La información recopilada se analizó y procesó con el programa estadístico de SPP versión 22, se realizó una estadística descriptiva de datos de consumo usando un análisis de frecuencias, medidas de tendencia central y de variabilidad, para el contraste de la prueba de hipótesis se utilizó la prueba de t- student. 


\section{CAPITTULO III}

\section{1.- RESULTADOS}

\section{Características generales de la población estudiada}

Tanto en el grupo control como el grupo experimental participaron igual cantidad de mujeres y hombres, así para cada grupo de 25 sujetos de estudio, el $76 \%$ (19) fueron hombres y el $24 \%$ (6) mujeres (ver el Gráfico $\left.N^{\circ} 1\right)$.

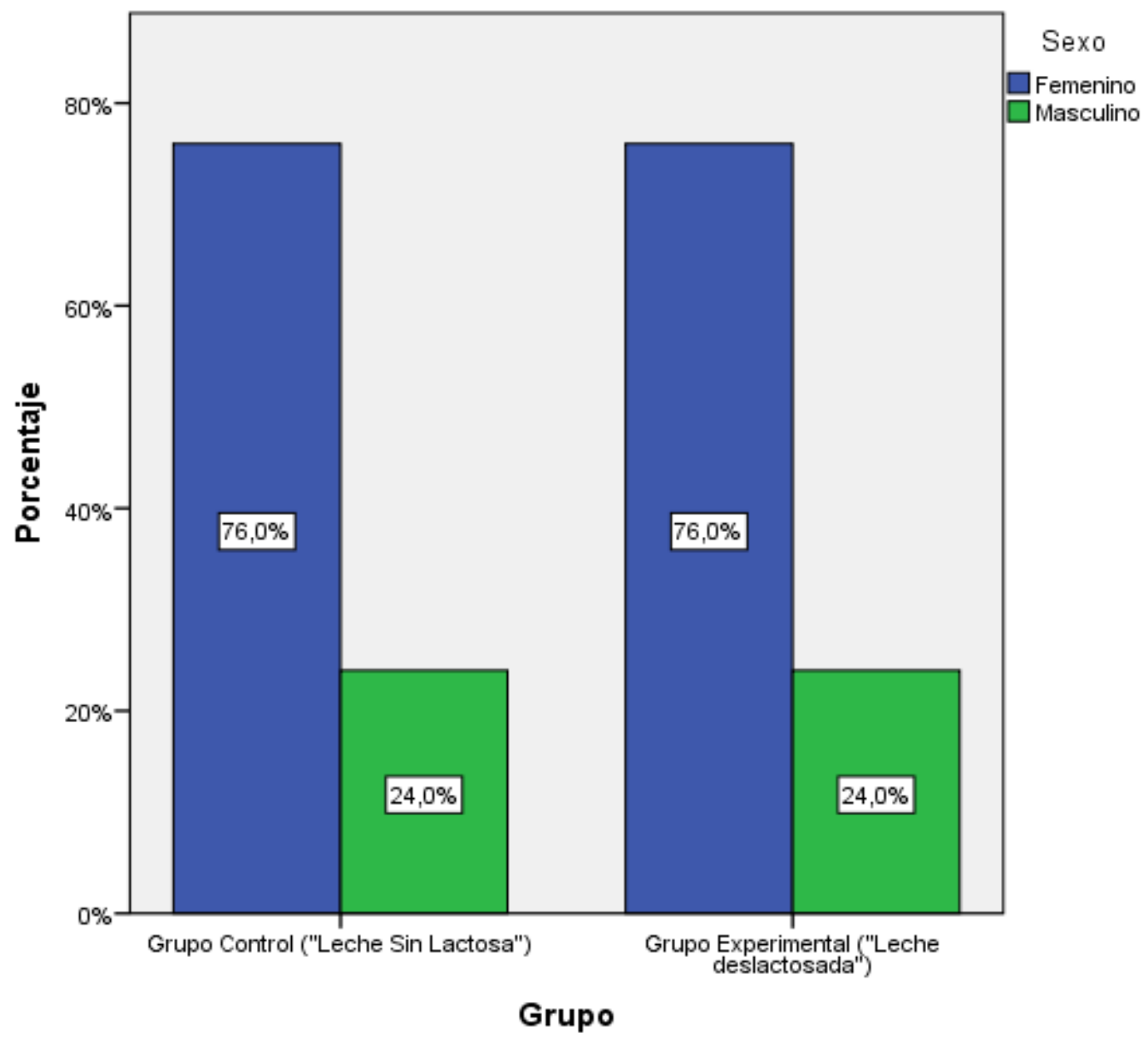

Figura 9. Distribución de personas según sexo en los grupos control y experimental

Fuente: Elaboración Propia. 
La media de las edades del total de participantes fue de 26 años $\pm 3,97$, con un error estándar de 0,562. Siendo la edad mínima de 20 y máxima de 35 .

El 48\% (24) de los participantes de la investigación indicaron consumir leche, mientras que el $52 \%$ (26) indicaron no consumirla (ver la tabla $N^{\circ} 3$ ).

\begin{tabular}{|ll|r|r|r|}
\hline & \multicolumn{2}{|c|}{ Consume Leche } & \multicolumn{2}{c|}{ Total } \\
\cline { 2 - 4 } & \multicolumn{1}{c|}{$\mathrm{Si}$} & \multicolumn{1}{c|}{ No } & \multicolumn{2}{|c|}{25} \\
\hline Grupo & 11 & 14 & $100,0 \%$ \\
& Grupo Control (Leche & $44,0 \%$ & $56,0 \%$ & 25 \\
& Sin lactosa) & 13 & 12 & $100,0 \%$ \\
\cline { 2 - 4 } & Grupo Experimental & $52,0 \%$ & $48,0 \%$ & 50 \\
\hline Total & 24 & 26 & $100,0 \%$ \\
\hline
\end{tabular}

Tabla $N^{\circ}$ 3. Participantes que consumen leche según grupo de evaluación

Fuente: Elaboración Propia.

De los participantes que indicaron consumir leche, en el grupo control los participantes consumieron "leche deslactosada" $73 \%$ (8) y "Sin lactosa" $27 \%$ (3), mientras que en el grupo experimental el 100\% (13) consumieron leche "Sin lactosa" (ver $\mathrm{N}^{\circ} 2$ ). 


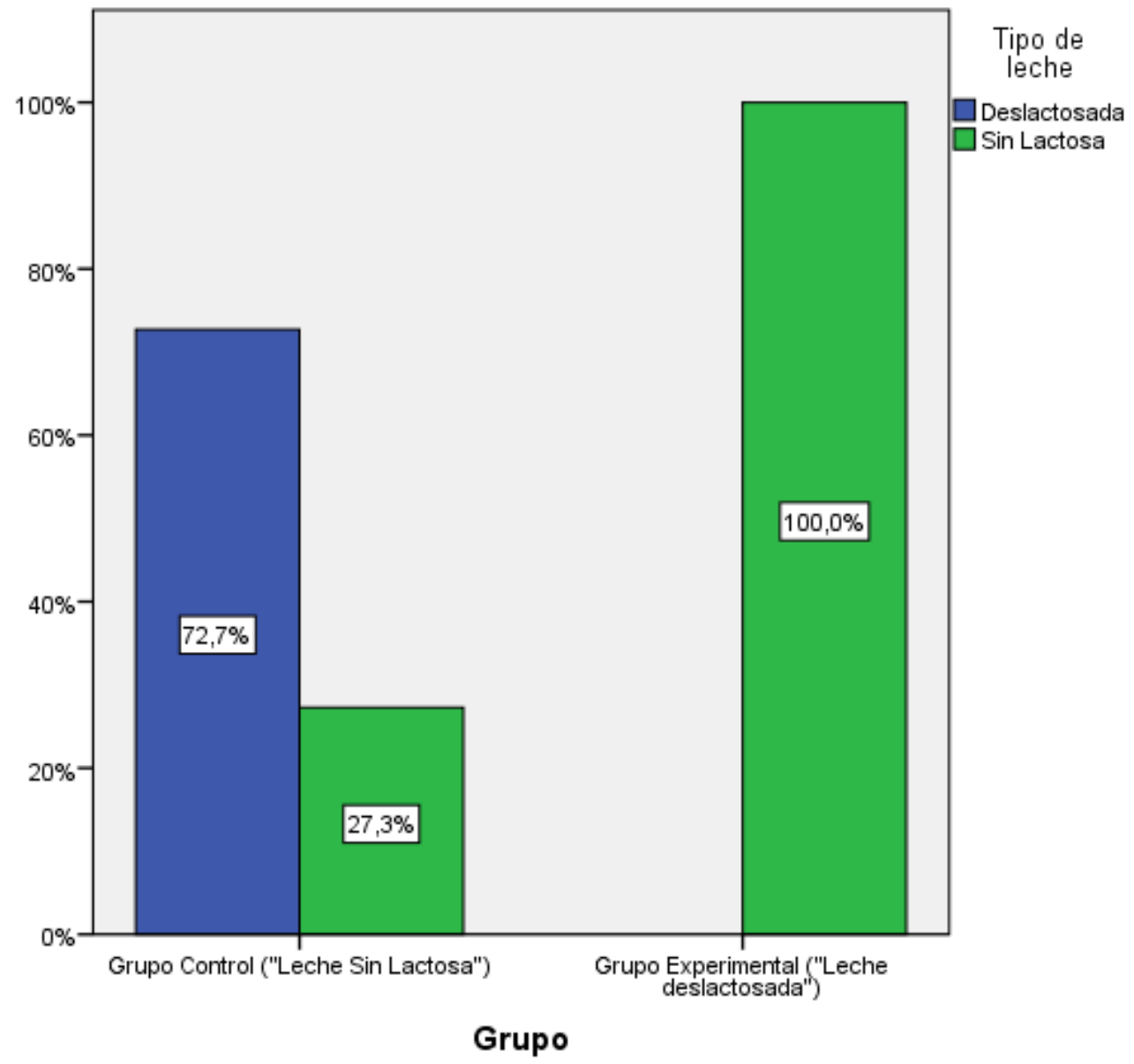

Figura 10. Tipo de leche consumida por las personas que indicaron consumir leche según grupo

Fuente: Elaboración Propia.

De los participantes que indicaron no consumir leche, en el grupo control el 92,9\% (13) fue por la convicción de que "les cae mal" y 7,1\% (1) porque "no les gusta", mientras que en el grupo experimental del 100\% (12) de los participantes indicaron que "les cae mal". 


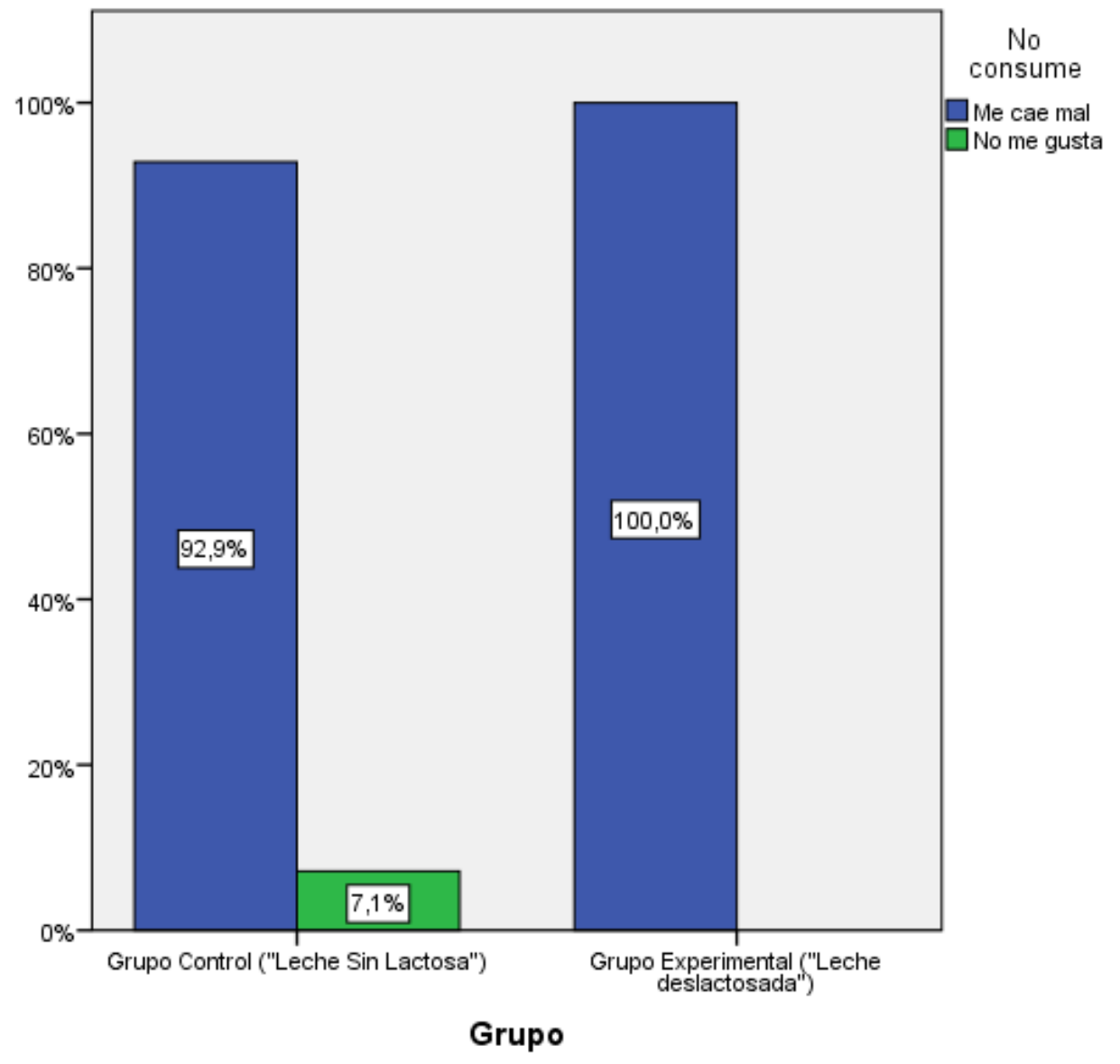

Figura 11. Motivos por lo cual las personas de los grupos evaluados indicaron no consumir leche

Fuente: Elaboración Propia

Intensidad de síntomas de intolerancia a la lactosa

La intensidad de los síntomas de intolerancia a la lactosa (diarrea, dolor abdominal, vómitos, borborigmos, distención abdominal, flatulencias, heces flotantes, cansancio, entre otros) reportados en el grupo control fue levemente menor al del grupo experimental. Más del $65 \%$ de los pacientes del grupo experimental no presentaron síntomas de intolerancia a la lactosa y más del $25 \%$ presentaron poco o síntomas de baja intensidad. 
Tabla $N^{\circ}$ 4. Intensidad de síntomas y signos de intolerancia evaluada en el primer día de la administración de las leches ofrecidas.

\begin{tabular}{|c|c|c|c|c|c|c|c|c|c|c|c|c|}
\hline \multirow[b]{2}{*}{ Síntomas y signos } & \multicolumn{6}{|c|}{ Grupo Control (“'Leche Sin Lactosa”) } & \multicolumn{6}{|c|}{ Grupo Experimental (“Leche deslactosada”) } \\
\hline & No & Poco & $\begin{array}{l}\text { Ni mucho } \\
\text { ni poco }\end{array}$ & Mucho & Intolerable & Total & No & Poco & $\begin{array}{c}\text { Ni mucho } \\
\text { ni poco }\end{array}$ & Mucho & Intolerable & Total \\
\hline Diarrea & $56 \%$ & $24 \%$ & $16 \%$ & $4 \%$ & $0 \%$ & $100 \%$ & $68 \%$ & $16 \%$ & $12 \%$ & $4 \%$ & $0 \%$ & $100 \%$ \\
\hline Dolor Abdominal & $56 \%$ & $24 \%$ & $12 \%$ & $4 \%$ & $4 \%$ & $100 \%$ & $68 \%$ & $12 \%$ & $12 \%$ & $8 \%$ & $0 \%$ & $100 \%$ \\
\hline Náuseas y Vómitos & $60 \%$ & $24 \%$ & $12 \%$ & $4 \%$ & $0 \%$ & $100 \%$ & $68 \%$ & $12 \%$ & $12 \%$ & $8 \%$ & $0 \%$ & $100 \%$ \\
\hline Borborigmos & $48 \%$ & $32 \%$ & $12 \%$ & $8 \%$ & $0 \%$ & $100 \%$ & $60 \%$ & $20 \%$ & $12 \%$ & $8 \%$ & $0 \%$ & $100 \%$ \\
\hline Distensión abdominal & $52 \%$ & $28 \%$ & $12 \%$ & $8 \%$ & $0 \%$ & $100 \%$ & $64 \%$ & $16 \%$ & $12 \%$ & $8 \%$ & $0 \%$ & $100 \%$ \\
\hline Flatulencias & $52 \%$ & $28 \%$ & $12 \%$ & $8 \%$ & $0 \%$ & $100 \%$ & $64 \%$ & $16 \%$ & $12 \%$ & $8 \%$ & $0 \%$ & $100 \%$ \\
\hline Heces flotantes & $64 \%$ & $24 \%$ & $8 \%$ & $4 \%$ & $0 \%$ & $100 \%$ & $80 \%$ & $8 \%$ & $4 \%$ & $8 \%$ & $0 \%$ & $100 \%$ \\
\hline Defecación explosiva & $72 \%$ & $20 \%$ & $8 \%$ & $0 \%$ & $0 \%$ & $100 \%$ & $76 \%$ & $12 \%$ & $4 \%$ & $8 \%$ & $0 \%$ & $100 \%$ \\
\hline Cansancio & $80 \%$ & $20 \%$ & $0 \%$ & $0 \%$ & $0 \%$ & $100 \%$ & $88 \%$ & $4 \%$ & $8 \%$ & $0 \%$ & $0 \%$ & $100 \%$ \\
\hline Nerviosismo & $64 \%$ & $24 \%$ & $8 \%$ & $4 \%$ & $0 \%$ & $100 \%$ & $80 \%$ & $12 \%$ & $4 \%$ & $4 \%$ & $0 \%$ & $100 \%$ \\
\hline Urticaria & $72 \%$ & $28 \%$ & $0 \%$ & $0 \%$ & $0 \%$ & $100 \%$ & $76 \%$ & $12 \%$ & $8 \%$ & $4 \%$ & $0 \%$ & $100 \%$ \\
\hline Trastornos respiratorios & $48 \%$ & $36 \%$ & $12 \%$ & $4 \%$ & $0 \%$ & $100 \%$ & $60 \%$ & $24 \%$ & $12 \%$ & $4 \%$ & $0 \%$ & $100 \%$ \\
\hline
\end{tabular}

Fuente: Elaboración Propia. 
Tabla $\mathrm{N}^{\circ}$ 5. Intensidad de síntomas de intolerancia a la lactosa según grupos evaluados

\begin{tabular}{|c|c|c|c|c|c|c|c|c|c|c|c|c|}
\hline \multirow[b]{2}{*}{ Características de Intolerancia } & \multicolumn{6}{|c|}{ Grupo Control ("Leche Sin Lactosa") } & \multicolumn{6}{|c|}{ Grupo experimental (“Leche deslactosada”) } \\
\hline & No & Poco & $\begin{array}{c}\text { Ni mucho } \\
\text { ni poco }\end{array}$ & Mucho & Intolerable & Total & No & Poco & $\begin{array}{c}\text { Ni mucho } \\
\text { ni poco }\end{array}$ & Mucho & Intolerable & Total \\
\hline \multirow{2}{*}{ Diarrea } & 292 & 60 & 17 & 4 & 2 & 375 & 248 & 93 & 23 & 11 & 0 & 375 \\
\hline & $77,9 \%$ & $16,0 \%$ & $4,5 \%$ & $1,1 \%$ & $0,5 \%$ & $100 \%$ & $66,1 \%$ & $24,8 \%$ & $6,1 \%$ & $2,9 \%$ & $0 \%$ & $100 \%$ \\
\hline \multirow{2}{*}{ Dolor abdominal } & 294 & 61 & 17 & 3 & 0 & 375 & 248 & 96 & 27 & 4 & 0 & 375 \\
\hline & $78,4 \%$ & $16,3 \%$ & $4,5 \%$ & $0,8 \%$ & $0 \%$ & $100 \%$ & $66,1 \%$ & $25,6 \%$ & $7,2 \%$ & $1,1 \%$ & $0 \%$ & $100 \%$ \\
\hline \multirow{2}{*}{ Vómitos o ganas de vomitar } & 294 & 61 & 17 & 3 & 0 & 375 & 248 & 96 & 27 & 4 & 0 & 375 \\
\hline & $78,4 \%$ & $16,3 \%$ & $4,5 \%$ & $0,8 \%$ & $0 \%$ & $100 \%$ & $66,1 \%$ & $25,6 \%$ & $7,2 \%$ & $1,1 \%$ & $0 \%$ & $100 \%$ \\
\hline \multirow{2}{*}{ Borborigmos } & 281 & 59 & 27 & 8 & 0 & 375 & 243 & 91 & 22 & 19 & 0 & 375 \\
\hline & $74,9 \%$ & $15,7 \%$ & $7,2 \%$ & $2,1 \%$ & $0 \%$ & $100 \%$ & $64,8 \%$ & $24,3 \%$ & $5,9 \%$ & $5,1 \%$ & $0 \%$ & $100 \%$ \\
\hline \multirow{2}{*}{ Distensión abdominal } & 290 & 55 & 22 & 8 & 0 & 375 & 255 & 83 & 18 & 19 & 0 & 375 \\
\hline & $77,3 \%$ & $14,7 \%$ & $5,9 \%$ & $2,1 \%$ & $0 \%$ & $100 \%$ & $68,0 \%$ & $22,1 \%$ & $4,8 \%$ & $5,1 \%$ & $0 \%$ & $100 \%$ \\
\hline \multirow{2}{*}{ Aumento de flatulencias } & 290 & 55 & 22 & 8 & 0 & 375 & 255 & 83 & 26 & 11 & 0 & 375 \\
\hline & $77,3 \%$ & $14,7 \%$ & $5,9 \%$ & $2,1 \%$ & $0 \%$ & $100 \%$ & $68,0 \%$ & $22,1 \%$ & $6,9 \%$ & $2,9 \%$ & $0 \%$ & $100 \%$ \\
\hline \multirow{2}{*}{ Heces flotantes y olor fétido } & 322 & 36 & 16 & 1 & 0 & 375 & 296 & 56 & 15 & 8 & 0 & 375 \\
\hline & $85,9 \%$ & $9,6 \%$ & $4,3 \%$ & $0,3 \%$ & $0 \%$ & $100 \%$ & $78,9 \%$ & $14,9 \%$ & $4,0 \%$ & $2,1 \%$ & $0 \%$ & $100 \%$ \\
\hline \multirow{2}{*}{ Defecación explosiva } & 316 & 40 & 18 & 1 & 0 & 375 & 293 & 54 & 24 & 4 & 0 & 375 \\
\hline & $84,3 \%$ & $10,7 \%$ & $4,8 \%$ & $0,3 \%$ & $0 \%$ & $100 \%$ & $78,1 \%$ & $14,4 \%$ & $6,4 \%$ & $1,1 \%$ & $0 \%$ & $100 \%$ \\
\hline \multirow{2}{*}{ Cansancio o abatimiento } & 346 & 25 & 4 & 0 & 0 & 375 & 332 & 32 & 11 & 0 & 0 & 375 \\
\hline & $92,3 \%$ & $6,7 \%$ & $1,1 \%$ & $0 \%$ & $0 \%$ & $100 \%$ & $88,5 \%$ & $8,5 \%$ & $2,9 \%$ & $0 \%$ & $0 \%$ & $100 \%$ \\
\hline \multirow{2}{*}{ Nerviosismo y trastornos del sueño } & 322 & 36 & 16 & 1 & 0 & 375 & 296 & 59 & 19 & 1 & 0 & 375 \\
\hline & $85,9 \%$ & $9,6 \%$ & $4,3 \%$ & $0,3 \%$ & $0 \%$ & $100 \%$ & $78,9 \%$ & $15,7 \%$ & $5,1 \%$ & $0,3 \%$ & $0 \%$ & $100 \%$ \\
\hline \multirow{2}{*}{ Enrojecimiento de la piel (urticaria) } & 316 & 45 & 13 & 1 & 0 & 375 & 293 & 58 & 22 & 2 & 0 & 375 \\
\hline & $84,3 \%$ & $12,0 \%$ & $3,5 \%$ & $0,3 \%$ & $0 \%$ & $100 \%$ & $78,1 \%$ & $15,5 \%$ & $5,9 \%$ & $0,5 \%$ & $0 \%$ & $100 \%$ \\
\hline
\end{tabular}


Trastornos respiratorios (Rinitis)

\begin{tabular}{|r|r|r|r|r|r|r|r|r|r|r|r|}
\hline 281 & 60 & 27 & 7 & 375 & 243 & 97 & 26 & 9 & 0 \\
\hline $74,9 \%$ & $16,0 \%$ & $7,2 \%$ & $1,9 \%$ & $0 \%$ & $100 \%$ & $64,8 \%$ & $25,9 \%$ & $6,9 \%$ & $2,4 \%$ & $0 \%$ & $100 \%$ \\
\hline
\end{tabular}

Fuente: Elaboración Propia. 
Al comparar los datos obtenidos de la intensidad de los síntomas de la lactosa en el grupo experimental y el grupo control, durante los 15 días del estudio se encontró lo siguiente:

\section{Tabla $N^{\circ}$ 6. Nivel de significancia de cada síntoma de intolerancia a la lactosa aplicando prueba de T-student}

\begin{tabular}{|l|c|}
\hline \multicolumn{1}{|c|}{ Síntoma de intolerancia a la lactosa } & Nivel de significancia ( $\mathbf{\alpha})$ \\
\hline Diarrea & 0,001 \\
\hline Dolor abdominal & 0,003 \\
\hline Vómitos o ganas de vomitar & 0,001 \\
\hline Borborigmos (ruidos de intestinos) & 0,009 \\
\hline Distención abdominal o meteorismo & 0,010 \\
\hline Aumento de flatulencias (gases) & 0,022 \\
\hline Heces flotantes y con olor fétido & 0,014 \\
\hline Defecación explosiva & 0,029 \\
\hline Cansancio y abatimiento & 0,042 \\
\hline Nerviosismo y trastornos del sueño & 0,048 \\
\hline Urticaria o eritema en labios & 0,024 \\
\hline Trastornos respiratorios (rinitis/asma) & 0,036 \\
\hline
\end{tabular}

Fuente: Elaboración Propia.

*Distribución normal y no se asumen varianzas iguales.

Se evidencia que la diferencia de síntomas y signos de intolernacia a la lactosa fueron significativos con un $\mathrm{p}<$ de 0,05 . 


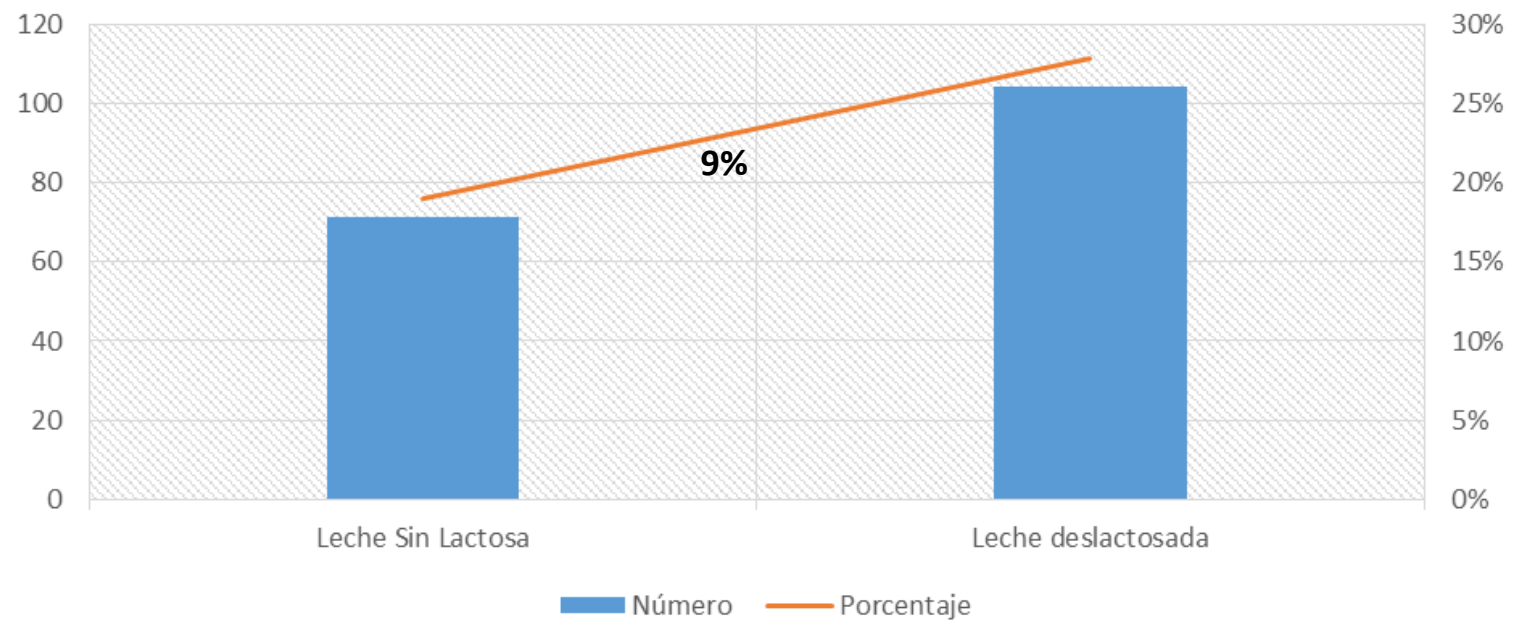

Figura 12. Distribución de participantes que presentaron síntomas de intolerancia a la lactosa al consumir leche deslactosada y leche sin lactosa.

En la figura se evidencia que existe diferencias de síntomas y signos producidos por la administración de leche deslactosada y sin lactosa, pero esta diferencia del $9 \%$ se encuentra entre el margen de equivalencia que se propuso que fue del $10 \%$ aceptable por su escasa relevancia clínica, por lo tanto, se rechaza la hipótesis nula. 


\section{2.- DISCUSIÓN}

La intolerancia a la lactosa afectaría aproximadamente al $70 \%$ de la población mundial. En Sudamérica, África y Asia, alrededor del $50 \%$ de la población ha reportado tener intolerancia a la lactosa ${ }^{1,2}$. La metabolización de la lactosa por las bacterias del colon se manifiesta por intolerancia con manifestaciones clínicas como flatulencias, diarrea, dolor abdominal, entre otros ${ }^{90}$. En nuestro estudio el $100 \%$ de los pacientes con intolerancia a la lactosa no consumían leche.

La manifestación de los síntomas de intolerancia a la lactosa depende de la dosis de lactosa consumida ${ }^{91}$. El panel de expertos de nutrición y alergias de la European Food Safety Authority ${ }^{5}$, indicó que no era posible determinar un umbral de lactosa para todas las personas con intolerancia a la lactosa porque existe una variación en las tolerancias individuales, sin embargo el panel concluyó que la mayoría de los sujetos con intolerancia a la lactosa podría tolerar hasta 12 gramos de lactosa en una sola dosis (particularmente si es consumida con otros alimentos) presentando poco o ningún síntoma, por lo que cantidades como $1,5 \mathrm{~g}$ (presente en una porción de leche Deslactosada) o menores a esta, pueden ser fácilmente toleradas sin la manifestación de síntomas. En nuestro estudio al grupo de intervención se le administró leche deslactosada conteniendo $15 \%$ de lactosa produciendo una baja frecuencia de síntomas y signos como diarrea, vómitos, distensión abdominal borgorismos, etc.

De la misma forma, un estudio de revisión ${ }^{92}$ indicó que la lactosa puede ser consumida en la alimentación como parte de los lácteos en cantidades moderadas, de $12 \mathrm{~g}$ hasta $24 \mathrm{~g}$ por día, preferentemente dividida en pequeñas cantidades durante el día.

Por otro lado, un estudio indica que, en los pacientes con intolerancia a la lactosa primaria, alguna actividad de la enzima lactasa persiste y "pequeñas" cantidades de lactosa pueden ser toleradas. Alrededor de 0,5 a 7,0 g de lactosa han demostrado no causar síntomas, al ser incluidos en la dieta ${ }^{7}$. Así, una leche libre de lactosa con otra con poca cantidad de lactosa no tiene diferencia en la severidad en los síntomas. Lo encontrado concuerda con la investigación realizada. 
Para menguar el problema de la intolerancia a la lactosa es consumir leche y productos lácteos cuyo contenido de lactosa se ha reducido en porcentaje de lactosa durante su proceso de obtención?

A raíz de los problemas de intolerancia a la lactosa, cada vez más frecuente en nuestro medio, la industria de alimentos desarrolla productos como la leche baja en lactosa, una leche en la que se ha reducido el contenido original de lactosa, debiendo esta reducción como mínimo el $30 \%$ sobre el contenido original. Estos tipos de leche son los indicados como parte del tratamiento dietético de la intolerancia a la lactosa, en estas se encuentran la leche sin lactosa o baja en lactosa ${ }^{93}$.

En un estudio en el cual se comparaba la ingesta de leche libre de lactosa con otra leche con lactosa hidrolizada, se encontró que personas que se denominaban así mismas como "intolerantes a la lactosa severas" atribuían erradamente los síntomas gastrointestinales a la intolerancia a la lactosa, cuando la ingesta de la leche fue limitad al equivalente de $240 \mathrm{ml}$ o menos al día, los síntomas fueron insignificantes. En nuestro estudio, la dieta fue más controlada, por lo tanto, los síntomas inducidos por la leche libre sin lactosa fueron muy suaves a comparación de la leche deslactosada y comparada con la leche sin lactosa hubo diferencias, pero no relevantes clínicamente.

Varios factores fisiológicos afectan los síntomas gastrointestinales más que pequeñas cantidades de lactosa no digerida, pudiendo resultar muy difícil controlar todos estos factores y estudiar los diferentes síntomas producidos por pequeñas cantidades de lactosa.

Nuestro estudio concordó con otros estudios sin embargo se recomienda establecer una línea de investigación sobre leche deslactosada cuyas proporciones bajas serán suficientes para mejorar la absorción de calcio y favorecer la función prebiótica.

A pesar de controlar los factores intervinientes el presente estudio no fue enmascarado lo que debilitó su validez interna, tampoco se puede extrapolar los resultados por tener un muestreo no probabilístico.

El porcentaje de síntomas y signos de intolerancia a la lactosa fueron bajos y bien tolerados lo que se propone es trabajar con proporciones bajas de lactosa, pero beneficiosas para mantener una fisiología adecuada del organismo. 
El presente estudio estuvo dirigido a la población adulta joven sin embargo se recomienda investigar en otros grupos como adolescentes y adultos mayores así mismo otras poblaciones de Lima.

Se obtuvo una significancia estadística encontrándose la diferencia dentro del margen de equivalencia lo que permitió establecer similitud de la leche deslactosada con la leche sin lactosa.

\section{3.- CONCLUSIONES}

- Se demostró que existen diferencias en los síntomas y signos característicos de la intolerancia a la lactosa en los pacientes de 16 a 30 años en los grupos de intervención con leche deslactosada conteniendo 15\% de lactosa y el grupo control sin lactosa, esta diferencia fue de $9 \%$, estando en el margen de equivalencia propuesto del 10\%, rechazándose la hipótesis nula, las diferencias de los síntomas y signos tuvieron una significancia con un $\mathrm{p}<0,05$.

- La leche deslactosada conteniendo lactosa al 15\% fue tolerada en adultos jóvenes con intolerancia a la lactosa de 16 a 30 años presentando una baja frecuencia de síntomas y signos de intolerancia a la lactosa.

- La leche sin lactosa fue también tolerada por adultos jóvenes con intolerancia a la lactosa de 16 a 30 años presentando una baja frecuencia de síntomas y signos de intolerancia a la lactosa muy similar a los efectos de la leche deslactosada.

- El $100 \%$ de los pacientes del grupo experimental antes de la intervención no consumían leche, el sexo predominante fue el femenino y la edad promedio de los sujetos estudiados fue $26 \pm 3,97$ años. 


\section{4.- RECOMENDACIONES}

- Teniendo en cuenta que la capacidad de absorber la lactosa, que está presente en la infancia y se pierde con la edad en un porcentaje variable de la población, debido a los hábitos de cambios en la ingesta o por otros factores fisiológicos y psicológicos provocando así la malabsorción de esta e influir en dicha intolerancia. Es fundamental encontrar la causa de estos y lograr obtener un correcto diagnóstico y no dejar de tener el beneficio propio de la lactosa presente en un producto lácteo.

- Se recomienda realizar un estudio longitudinal para medir el efecto de la activación de la enzima lactasa al tener continuidad del consumo de una leche con lactosa en comparación con unas cero lactosas.

- Se recomienda realizar un estudio para medir la mineralización ósea en personas que consumieron una leche cero lactosas frente a las que hayan consumido menos de 6 gramos de lactosa en cada toma.

- Se recomienda un estudio en los diversos tipos de intolerancia a la lactosa para medir el nivel de tolerancia a la lactosa en cada grupo y esto ayude a tener un menor porcentaje de diferencia en los resultados. 


\section{BIBLIOGRAFİA}

1. Muehlhoff, E., Bennett, A., \& McMahon, D. Milk and dairy products in human nutrition. Food and Agriculture Organization of the United Nations (FAO). 2013. E-ISBN 978-92-5-107864-8 (PDF).

2. Lomer MC, Parkes GC, Sanderson JD. Review article: lactose intolerance in clinical practice--myths and realities. Aliment Pharmacol Ther. 2008 Jan 15;27(2):93-103. Epub 2007 Oct 23.

3. Swallow DM. Genetics of lactase persistence and lactose intolerance. Annu Rev Genet. 2003; 37:197-219.

4. Heyman MB; Committee on Nutrition. Lactose intolerance in infants, children, and adolescents. Pediatrics. 2006 Sep;118(3):1279-86.

5. EFSA Panel on Dietetic Products, Nutrition and Allergies (NDA). Scientific Opinion on lactose thresholds in lactose intolerance and galactosaemia. EFSA Journal 2010;8(9): 1777:29.

6. Nicklas TA, Qu H, Hughes SO, He M, Wagner SE, Foushee HR, et al. Selfperceived lactose intolerance results in lower intakes of calcium and dairy foods and is associated with hypertension and diabetes in adults. Am J Clin Nutr. 2011 Jul;94(1):191-8. doi: 10.3945/ajcn.110.009860. Epub 2011 Apr 27.

7. Vandenplas Y. Lactose intolerance. Asia Pac J Clin Nutr. 2015;24 Suppl 1:S913. doi: 10.6133/apjen.2015.24.s1.02.

8. Mark Fox et al, 2013

9. Vénica C, Perotti M, Wolf I, Bergamini C, Zalazar C. Intolerancia a la lactosa. Productos lácteos modificados. Nutrición y Salud. Tecnología Láctea Latinoamericana. 2011;(65):50-57. Disponible en: https://www.researchgate.net/publication/281589062 Intolerancia a la lactos a Productos lacteos modificados 
10. Alvarado - Ortiz C, Blanco T. Alimentos. Bromatología. $2^{2}$ ed. Lima, Perú: Universidad Peruana de Ciencias Aplicadas SAC; 2008.

11. Castellano E, Palomino e, Tabraue C. Biología general. Las Palmas de Gran Canaria: Universidad de Las Palmas de Gran Canaria. Servicio de Publicaciones y Difusión Científica; 2015. Available from: ProQuest Ebook Central ISBN 978-84-9042-217-5

12. Juraschek SP, Miller ER 3rd, Selvin E, Carey VJ, Appel LJ, Christenson RH, et al. Effect of type and amount of dietary carbohydrate on biomarkers of glucose homeostasis and $\mathrm{C}$ reactive protein in overweight or obese adults: results from the OmniCarb trial. BMJ Open Diabetes Res Care. 2016 Nov 14;4(1):e000276. eCollection 2016.

13. Widjaja L, Safarina G. M, Surono I, Wahlqvist M. From 'lactose intolerance' to 'lactose nutrition'. Asia Pac J Clin Nutr 2015;24(Suppl 1):S1-S8. S1

14. Furnes $R$, Láquis $M$. Nutrición infantil en lactantes niños y adolescentes. Córdoba: Editorial Brujas; 2016. Available from: ProQuest Ebook Central ISBN 978-987-591-760-6

15. Levin RJ Digestion and absorption of carbohydrates-from molecules and membranes to humans. Am J Clin Nutr. 1994;59: 690S-698S.

16. Hediger MA, Turk E, Wright E. Homology of the human intestinal $\mathrm{Na}+$ /glucose and E. coli $\mathrm{Na}+$ /proline cotransporters. Proc Natl Acad Sci USA. 1989;86:5748-5752.

17. Bell GI, Kayano T, Buse JB, Burant CF, Takeda J, Lin D, Fukumoto H, Seino S. Molecular biology of mammalian glucose transporters. Diabetes Care. 1990;13:198-208.

18. Wright EM, Turk E, Zabel B, Mundlos S, Dyer J. Molecular genetics of intestinal glucose transport. J Clin Invest. 1991;88:1435-1440

19. Crane RK. Hypothesis for mechanism of intestinal active transport of sugars. Fed Proc. 1962; 21:891-895.

20. Wright EM, Martin MG, Turk E. Intestinal absorption in health and diseasesugars. Best Pract Res Clin Gastroenterol. 2003; 17:943-956.

21. Wright EM, Turk E, Martin MG. The molecular basis for glucosegalactose malabsorption. Cell Biochem Biophys. 2002; 36:115-121. 
22. Meeuwisse GW, Melin K. Glucose-galactose malabsorption a clinical study of 6 cases. Acta Pediatr Scand. 1969; 188[Suppl]:1-24

23. Mathews, C.K.; Van Holde, K.E.; Ahern K.G. Bioquímica. Hidratos de carbono. 5ta ed. 2002.

24. Agudelo D, Bedoya O. Composición nutricional de la leche de ganado vacuno. Revista Lasallista de Investigación. 2005 Jun;4(1):38-42. ISSN: 1794-4449.

25. Lerche M. Inspección veterinaria de la leche. Ed Acribia;Zaragoza España. 1.69:p188

26. Wattiaux M, Howard T. digestión en la vaca lechera. Instituto Babcock para la Investigación y Desarrollo Internacional de la Industria Lechera Universidad de Wisconsin-Madison. Disponible en https://es.scribd.com/doc/71923814/Guia-Tecnica-Basica-de-lecheriaUniversidad-de-Wisconsin-Madison

27. MINISTERIO DE SALUD. Decreto 2437 por elcual se reglamenta parcialmente el Título $\mathrm{V}$ dela Ley 9a de 1979, en cuanto a Producción,Procesamiento, Transporte y Comercializaciónde la leche, agosto 30 de 1893

28. Wahlqvist ML. Lactose nutrition in lactase nonpersisters. Asia Pac J Clin Nutr. 2015;24(Suppl 1):S21-5

29. Harvey CB, Hollox EJ, Poulter M, Wang Y, Rossi M, Auricchio S, et al. Lactase haplotype frequencies in Caucasians: association with the lactase persistence/nonpersistence polymorphism. Ann Hum Genet. 1998;62:215-23.

30. Simoons FJ. Primary adult lactose intolerance and the milking habit: a problem in biologic and cultural interrelations. II. A culture historical hypothesis. Am J Dig Dis. 1970;15:695-710.

31. Allentoft ME, Sikora M, Sjögren KG, Rasmussen S, Rasmussen M, Stenderup $\mathrm{J}$, et al. Population genomics of Bronze Age Eurasia. Nature. 2015;522:16772

32. Lebenthal E, Antonowicz I, Shwachman H. Correlation of lactase activity, lactose tolerance and milk consumption in different age groups. Am J Clin Nutr. 1975;28:595-600. 
33. Welsh JD, Poley JR, Bhatia M, Stevenson DE. Intestinal disaccharidase activities in relation to age, race, and mucosal damage. Gastroenterology.1978;75:847-55.

34. Sánchez-Ávila M, Chávez Caraza K, González Gil A, Cantú Pompa J, Moreno Medrano E, Morales-Garza L. Correlación entre los síntomas digestivos y los resultados de una prueba de hidrógeno en aliento en el diagnóstico de intolerancia a carbohidratos. Rev Gastroenterol Peru. 2016;36(3):225-30

35. Davidson GP, Goodwin D, Robb TA. Incidence and duration of lactose malabsorption in children hospitalized with acute enteritis: study in a wellnourished urban population. J Pediatr. 1984;105:587-90.

36. MacGillivray S, Fahey T, McGuire W. Lactose avoidance for young children with acute diarrhoea. Cochrane Database Syst Rev. 2013:CD005433.

37. Koletzko S, Heine RG. Non-IgE mediated cow's milk allergy in EuroPrevall. Allergy. 2015;70:1679-80

38. Wauters L, Brown T, Venter C, Dziubak R, Meyer R, Brogan B, et al. Cow's milk allergy prescribing is influenced by regional and National Guidance. J Pediatr Gastroenterol Nutr. 2016;62:765-70

39. Wojcik KY, Rechtman DJ, Lee ML, Montoya A, Medo ET. Macronutrient analysis of a nationwide sample of donor breast milk. J Am Diet Assoc. 2009;109:137-40

40. Bissett DL, Anderson RL. Lactose and D-galactose metabolism in group N streptococci: presence of enzymes for both the D-galactose 1-phosphate and D-tagatose 6-phosphate pathways. J Bacteriol. 1974;117:318-20

41. Bond JH, Levitt MD. Quantitative measurement of lactose absorption. Gastroenterology. 1976;70:1058-62.

42. Harvey CB, Fox MF, Jeggo PA, Mantei N, Povey S, Swallow DM. Regional localization of the lactase-phlorizin hydrolase gene, LCT, to chromosome 2q21. Ann Hum Genet. 1993;57:179-85.

43. Antonowicz I, Lebenthal E. Developmental pattern of small intestinal enterokinase and disaccharidase activities in the human fetus. Gastroenterology. 1977;72:1299-303 
44. Buller HA, Van Wassenaer AG, Raghavan S, Montgomery RK, Sybicki MA, Grand RJ. New insights into lactase and glycosylceramidase activities of rat lactase-phlorizin hydrolase. Am J Phys. 1989;257:G616-23.

45. Wang Y, Harvey CB, Hollox EJ, Phillips AD, Poulter M, Clay P, Walker-Smith JA, Swallow DM. The genetically programmed down-regulation of lactase in children. Gastroenterology. 1998;114:1230-6.

46. Bulhoes AC, Goldani HA, Oliveira FS, Matte US, Mazzuca RB, Silveira TR. Correlation between lactose absorption and the C/T-13910 and G/A-22018 mutations of the lactase-phlorizin hydrolase (LCT) gene in adult-type hypolactasia. Braz J Med Biol Res. 2007;40:1441-6

47. Kuchay RA, Anwar M, Thapa BR, Mahmood A, Mahmood S. Correlation of G/ a -22018 single-nucleotide polymorphism with lactase activity and its usefulness in improving the diagnosis of adult-type hypolactasia among north Indian children. Genes Nutr. 2013;8:145-51

48. Xu L, Sun H, Zhang X, Wang J, Sun D, Chen F, Bai J, Fu S. The -22018A allele matches the lactase persistence phenotype in northern Chinese populations. Scand J Gastroenterol. 2010;45:168-74

49. Enattah NS, Jensen TG, Nielsen M, Lewinski R, Kuokkanen M, Rasinpera H, et al. Independent introduction of two lactase-persistence alleles into human populations reflects different history of adaptation to milk culture. Am J Hum Genet. 2008;82:57-72

50. Macholdt E, Slatkin M, Pakendorf B, Stoneking M. New insights into the history of the C-14010 lactase persistence variant in eastern and southern Africa. Am J Phys Anthropol. 2015;156:661-4.

51. Tishkoff SA, Reed FA, Ranciaro A, Voight BF, Babbitt CC, Silverman JS, et al. Convergent adaptation of human lactase persistence in Africa and Europe. Nat Genet. 2007;39:31-40.

52. Dzialanski Z, Barany $M$, Engfeldt $P$, Magnuson A, Olsson LA, Nilsson TK. Lactase persistence versus lactose intolerance: is there an intermediate phenotype? Clin Biochem. 2016;49:248-52.

53. Itan Y, Jones BL, Ingram CJ, Swallow DM, Thomas MG. A worldwide correlation of lactase persistence phenotype and genotypes. BMC Evol Biol. 2010;10:36. 
54. Scrimshaw NS, Murray EB. The acceptability of milk and milk products in populations with a high prevalence of lactose intolerance. Am J Clin Nutr. 1988;48:1079-159.

55. Tan-Dy CR, Ohlsson A. Lactase treated feeds to promote growth and feeding tolerance in preterm infants. Cochrane Database Syst Rev. 2005:CD004591

56. Erasmus HD, Ludwig-Auser HM, Paterson PG, Sun D, Sankaran K. Enhanced weight gain in preterm infants receiving lactase-treated feeds: a randomized, double-blind, controlled trial. J Pediatr. 2002;141:532-7.

57. Rasinpera H, Savilahti E, Enattah NS, Kuokkanen M, Totterman N, Lindahl H, et al. A genetic test which can be used to diagnose adult-type hypolactasia in children. Gut. 2004;53:1571-6.

58. Hegar B, Widodo A. Lactose intolerance in Indonesian children. Asia Pac J Clin Nutr. 2015;24(Suppl 1):S31-40.

59. Swiatkowski E, Socha J. Lactose-intolerance and hypolactasia in children with giardiasis. J Pediatr Gastroenterol Nutr. 1990;11:424-5.

60. Heine RG. Pathophysiology, diagnosis and treatment of food proteininduced gastrointestinal diseases. Curr Opin Allergy Clin Immunol. 2004;4:221-9

61. Prasad KK, Thapa BR, Nain CK, Sharma AK, Singh K. Brush border enzyme activities in relation to histological lesion in pediatric celiac disease. J Gastroenterol Hepatol. 2008;23:e348-52.

62. von Tirpitz C, Kohn C, Steinkamp M, Geerling I, Maier V, Moller P, et al. Lactose intolerance in active Crohn's disease: clinical value of duodenal lactase analysis. J Clin Gastroenterol. 2002;34:49-53.

63. Heyman MB, Committee on N. Lactose intolerance in infants, children, and adolescents. Pediatrics. 2006;118:1279-86.

64. Lucassen PL, Assendelft WJ, Gubbels JW, van Eijk JT, van Geldrop WJ, Neven AK. Effectiveness of treatments for infantile colic: systematic review. BMJ. 1998;316:1563-9

65. Savaiano DA, Boushey CJ, McCabe GP. Lactose intolerance symptoms assessed by meta-analysis: a grain of truth that leads to exaggeration. J Nutr. 2006;136:1107-13.

66. Staudacher HM, Whelan K, Irving PM, Lomer MC. Comparison of symptom response following advice for a diet low in fermentable carbohydrates 
(FODMAPs) versus standard dietary advice in patients with irritable bowel syndrome. J Hum Nutr Diet. 2011;24:487-95.

67. Distefano M, Certo M, Colecchia A, Sorge M, Perri F. H2breath tests: methodological audits in adults and children. Aliment Pharmacol Ther. 2009;29(1):8-12.

68. Rana S, Malik A. Hydrogen breath tests in gastrointestinal diseases. Indian J Clin Biochem. 2014;29(4):398-405.

69. Usai Satta P, Anania C, Astegiano M, Miceli E, Montalto M, Tursi A. H2-breath testing for carbohydrate malabsorption. Aliment Pharmacol Ther. 2009; 29 Suppl 1:14-7.

70. Rezaie A, Buresi M, Lembo A, Lin H, McCallum R, Rao S, et al. Hydrogen and methane-based breath testing in gastrointestinal disorders: the north American consensus. Am J Gastroenterol. 2017;112:775-84

71. Moran S, Mina A, Duque X, Anaya S, San-Martin U, Yanez P, Rodriguez-Leal G. Prevalence of lactose malabsorption in Mexican children: importance of measuring methane in expired air. Arch Med Res. 2013;44:291-5

72. Medow MS, Glassman MS, Schwarz SM, Newman LJ. Respiratory methane excretion in children with lactose intolerance. Dig Dis Sci. 1993;38:328-32.

73. Glatstein M, Reif S, Scolnik D, Rom L, Yerushalmy-Feler A, Dali-Levy M, Cohen S. Lactose breath test in children: relationship between symptoms during the test and test results. Am J Ther. 2016; epub ahead of print.

74. Nieminen U, Kahri A, Savilahti E, Farkkila MA. Duodenal disaccharidase activities in the follow-up of villous atrophy in coeliac disease. Scand $J$ Gastroenterol. 2001;36:507-10.

75. Asp NG, Dahlqvist A, Kuitunen P, Launiala K, Visakorpi JK. Complete deficiency of brush-border lactase in congenital lactose malabsorption. Lancet. 1973;2:329-30

76. Levitt M, Wilt T, Shaukat A. Clinical implications of lactose malabsorption versus lactose intolerance. J Clin Gastroenterol. 2013;47:471-80.

77. Montalto M, Gallo A, Santoro L, D'Onofrio F, Curigliano V, Covino M, et al. Low-dose lactose in drugs neither increases breath hydrogen excretion nor causes gastrointestinal symptoms. Aliment Pharmacol Ther. 2008;28:1003-12 
78. Sanders SW, Tolman KG, Reitberg DP. Effect of a single dose of lactase on symptoms and expired hydrogen after lactose challenge in lactoseintolerant subjects. Clin Pharm. 1992;11:533-8

79. Medow MS, Thek KD, Newman LJ, Berezin S, Glassman MS, Schwarz SM. Beta-galactosidase tablets in the treatment of lactose intolerance in pediatrics. Am J Dis Child. 1990;144:1261-4

80. Chew F, Villar J, Solomons NW, Figueroa R. In vitro hydrolysis with a betagalactosidase for treatment of intolerance to human milk in very low birthweight infants. Acta Paediatr Scand. 1988;77:601-2.

81. Abrams SA, Griffin IJ, Davila PM. Calcium and zinc absorption from lactosecontaining and lactose-free infant formulas. Am J Clin Nutr. 2002;76:442-6

82. Niggemann B, von Berg A, Bollrath C, Berdel D, Schauer U, Rieger C, et al. Safety and efficacy of a new extensively hydrolyzed formula for infants with cow's milk protein allergy. Pediatr Allergy Immunol. 2008;19:348-54

83. Vandenplas Y, Steenhout P, Planoudis Y, Grathwohl D, Althera SG. Treating cow's milk protein allergy: a double-blind randomized trial comparing two extensively hydrolysed formulas with probiotics. Acta Paediatr. 2013;102:9908

84. Zingone F, Bucci $\mathrm{C}$, lovino $\mathrm{P}$, Ciacci $\mathrm{C}$. Consumption of milk and dairy products: facts and figures. Nutrition. 2017;33:322-5.

85. Almon R, Sjöström M, Nilsson TK. Lactase non-persistence as a determinant of milk avoidance and calcium intake in children and adolescents. J Nutr Sci. 2013;2:e26.

86. Fox AT, Du Toit G, Lang A, Lack G. Food allergy as a risk factor for nutritional rickets. Pediatr Allergy Immunol. 2004;15:566-9.

87. Doulgeraki AE, Manousakis EM, Papadopoulos NG. Bone health assessment of food allergic children on restrictive diets: a practical guide. J Pediatr Endocrinol Metab. 2017;30:133-9.

88. Heaney RP. Dairy intake, dietary adequacy, and lactose intolerance. Adv Nutr. 2013;4:151-6. 
89. Cochet B, Jung A, Griessen M, Bartholdi P, Schaller P, Donath A. Effects of lactose on intestinal calcium absorption in normal and lactase-deficient subjects. Gastroenterology. 1983;84:935-40.

90. de Vrese M, Stegelmann A, Richter B, Fenselau S, Laue C, Schrezenmeir J. Probiotics--compensation for lactase insufficiency. Am J Clin Nutr. 2001 Feb;73(2 Suppl):421S-429S.

91. Hertzler SR, Huynh BC, Savaiano DA. How much lactose is low lactose? J Am Diet Assoc. 1996 Mar;96(3):243-6. DOI: 10.1016/S0002-8223(96)00074-0

92. Lukito, SG Malik, IS Surono and ML Wahlqvist, 2015

93. Infante Pina D, Peña Quintana L, Sierra Salinas C. Intolerancia a la lactosa/Lactose intolerance. Acta Pediatr Esp. 2015;73(10):249-258. ID MEDES: 105939.

94. Poveda, E. Suero lácteo, generalidades y potencial uso como fuente de calcio de alta biodisponibilidad. Revista chilena de nutrición.2013;40(4):397-403.

95. Gänzle M, Bryans J, Jelen P, Smithers G. Nutrition and health aspects of lactose and its derivatives: State of the science. International Dairy Journal. 2012;22(2):87. doi: 10.1016/j.idairyj.2011.11.001. 40

96. Moreira V. F, López A. Intolerancia a la lactosa. Rev Esp Enferm Dig. 2006 Feb;98(2). ISSN 1130-0108 Disponible en:

http://scielo.isciii.es/scielo.php?script=sci arttext\&pid=S1130-01082006000200009

97. Alvarado - Ortiz C, Blanco T. Repasando Bioquímica y Nutrición. Lima: Fondo Editorial Universidad San Martín de Porres; 2012.

98. Quevedo L, Rojas M, Soto M. "Intolerancia a la lactosa". Revista de pediatría electrónica. 2011 Dic;8(3). Disponible en: http://www.revistapediatria.cl/volumenes/2011/vol8num3/4.html

99. Medina I. Desarrollo de un helado reducido en lactosa [Tesis]. Argentina: Instituto universitario en ciencias de la salud. Fundación H.A.Barcelo. Facultad de medicina; 2014. Disponible en http://www.barcelo.edu.ar/greenstone/collect/tesis/index/assoc/HASHfd5a.dir/TFI\% 20Medina\%20Ines.pdf

100. Posada K, Terán D, Ramírez-Navas J. Empleo de lactosuero y sus componentes en la elaboración de postres y productos de confitería. La alimentación latinoamericana. 2011;(292):66-75. Disponible en: http://www.academia.edu/28352669/Empleo de lactosuero y sus componentes en la elaboraci\%C3\%B3n de postres y productos de confiter\%C3\%ADa 


\section{ANEXOS}

\section{Instrumentos}

\section{Encuesta $\mathrm{N}^{\circ} 1$ de Consumo de lácteos}

Fecha:

Nombre:

Fecha de Nacimiento:

$N^{\circ}$ Encuesta:

Lugar de origen:

Edad:

Dirección:

C,C,:

Estrato Socioeconómico:

Teléfono:

Talla:

1. ¿Consume usted leche?

Peso:
a. Si

b. No

1,1 ¿Qué tipo de leche consume? Y ¿con qué frecuencia a la semana? Y ¿cuál es la cantidad consumida por vez?
a. Entera (Azul)
b. Light (Roja)

c. Súper light (blanca con letras roja)

d. Deslactosada (celeste)

e. 0 lactosa ( especifique)

f. Otro:

1,2 , Si su respuesta es no, ¿Por qué no consume leche?

a. Me cae mal

b. No me gusta

c. Me lo prohibieron

d. Otro: 
ENCUESTA N 2 PARA MEDIR EL GRADO DE TOLERANCIA A LACTOSA EN PACIENTES INTOLERANTES QUE ESTÁN RECIBIENDO LECHES CON DIVERSAS CONCENTRACIONES COMERCIALES DE LACTOSA

Apellidos y Nombres:

Encuesta Número:

Clave de inclusión en el trabajo:

Fecha de inicio de la participación:

Fecha de la encuesta:

La encuesta que se le va realizar, sirve para valorar la cantidad de azúcar de la leche (lactosa) que usted puede tolerar. Se le está suministrando leche con baja concentración de lactosa o completamente sin lactosa. Usted ignora el grupo al que pertenece (Baja concentración de lactosa o sin lactosa).

Para contestar, identifique los síntomas o signos que apreció durante la semana después de tomar el vaso de leche.

1. ¿Ha tenido diarrea (estómago suelto) durante la prueba?
a. No
b. poco
c. Ni mucho ni poco
d. Mucho
e. intolerable

2. ¿Ha tenido dolor abdominal (de barriga como retortijones de intestino) durante la prueba?
a. No
b. Poco
c. Ni mucho ni poco
d. Mucho
e. Intolerable

3. ¿Ha tenido vómitos o ganas de vomitar durante la prueba?
a. No
b. Poco
c. Ni mucho ni poco
d. Mucho
e. Intolerable

4. ¿Ha tenido borborigmos (ruidos de tripas) durante la prueba?
a. No
b. Poco
c. Ni mucho ni poco 

d. Mucho
e. Intolerable

5. ¿Ha tenido distensión abdominal, o meteorismo durante la prueba?
a. No
b. Poco
c. Ni mucho ni poco
d. Mucho
e. Intolerable

6. ¿Ha presentado aumento de flatulencias (gases) durante la prueba?
a. No
b. Poco
c. Ni mucho ni poco
d. Mucho
e. Intolerable

7. ¿Ha presentado heces flotantes y con olor fétido durante la prueba?
a. No
b. Poco
c. Ni mucho ni poco
d. Mucho
e. Intolerable

8. ¿Ha presentado defecación explosiva durante la prueba?
a. No
b. Poco
c. Ni mucho ni poco
d. Mucho
e. Intolerable

9. ¿Ha presentado cansancio, abatimiento durante la prueba?
a. No
b. Poco
c. Ni mucho ni poco
d. Mucho
e. Intolerable

10. ¿Ha presentado nerviosismo y trastornos del sueño durante la prueba?
a. No
b. Poco
c. Ni mucho ni poco 

d. Mucho
e. Intolerable

11. ¿Ha presentado Rush cutáneos (enrojecimiento de piel), urticaria (picazón) o eritema de labios, durante el período?
a. No
b. Poco
c. Ni mucho ni poco
d. Mucho
e. Intolerable

12. ¿Ha presentado trastornos respiratorios como rinitis y asma durante el período?
a. No
b. Poco
c. Ni mucho ni poco
d. Mucho
e. Intolerable 


\section{Consentimiento Informado \\ - JÓVENES ADULTOS -}

Institución : : Universidad San Ignacio de Loyola

Investigadora : $\quad$ Magister Youmi Paz Olivas

Título : Efecto de la leche deslactosada comparada con la leche sin lactosa en adolescentes y adultos jóvenes de 13 a 35 años intolerantes a la lactosa del hospital Hipólito Unanue del distrito del Agustino de Lima Metropolitana.

\section{Propósito del Estudio:}

Lo (a) estoy invitando a participar en un estudio llamado: Efecto de la leche deslactosada comparada con la leche sin lactosa en adolescentes y adultos jóvenes de 13 a 35 años intolerantes a la lactosa del hospital Hipólito Unanue del distrito del Agustino de Lima metropolitana.

Este es un estudio desarrollado por la Magister Youmi Paz Olivas, nutricionista de formación para obtener el grado académico de Doctora en Universidad San Ignacio de Loyola. Estoy realizando este estudio para lograr tener alternativas dentro del mercado de la industria de productos deslactosados que ayuden a disminuir los síntomas de un intolerante a la lactosa.

\section{Procedimientos:}

Si usted acepta participar en este estudio se le harán los siguientes procedimientos:

1. Se utilizará una ficha de recolección de datos donde se le harán diversas preguntas sobre su consumo de leche su aceptabilidad y la frecuencia de consumo.

2. Se le invitará que consuma un vaso de leche (Ud. No sabrá la marca ni el tipo de leche).

3. Finalmente se le realizará una encuesta para ver la tolerancia y los síntomas presentados al tomar la leche ofrecida.

\section{Riesgos:}

No se prevén riesgos por participar en esta fase del estudio. 


\section{Beneficios:}

Usted se beneficiará de una evaluación de la tolerancia al producto ofrecido.

\section{Costos e incentivos}

Usted no deberá pagar nada por participar en el estudio. Y se le entregará productos lácteos que ayudarán en su tratamiento nutricional para intolerantes a la lactosa

\section{Confidencialidad:}

Nosotros guardaremos su información con códigos y no con nombres. Si los resultados de este seguimiento son publicados, no se mostrará ninguna información que permita la identificación de las personas que participan en este estudio. Sus archivos no serán mostrados a ninguna persona ajena al estudio sin su consentimiento.

\section{Derechos del paciente:}

Si usted decide participar en el estudio, puede retirarse de éste en cualquier momento, o no participar en una parte del estudio sin perjuicio alguno. Si tiene alguna duda adicional, por favor pregunte al personal del estudio, o llamar a la Lic. Youmi Paz Olivas al 961079191.

Si usted tiene preguntas sobre los aspectos éticos del estudio, o cree que ha sido tratado injustamente puede contactar al Comité Institucional de Ética de la Universidad Peruana Cayetano Heredia, teléfono $01-319000$ anexo 2271

\section{CONSENTIMIENTO}

Acepto voluntariamente participar en este estudio, comprendo que cosas me van a pasar si participo en el proyecto, también entiendo que puedo decidir no participar y que puedo retirarme del estudio en cualquier momento.

\section{Participante}

Nombre:

DNI:

\section{Testigo}

Nombre:

DNI:

\section{Fecha}

Fecha 


\section{MATRIZ DE CONSISTENCIA}

\section{Síntomas de intolerancia a la lactosa en consumidores "leche deslactosada" comparada con la "leche sin lactosa" del Hospital Hipólito Unanue del 2015}

\begin{tabular}{|c|c|c|c|}
\hline PROBLEMA & OBJETIVOS & HIPOTESIS & $\begin{array}{l}\text { VARIABLES E } \\
\text { INDICADORES }\end{array}$ \\
\hline $\begin{array}{l}\text { Problema General } \\
\text { ¿Existe diferencias de los síntomas y signos } \\
\text { característicos de la intolerancia a la lactosa en los } \\
\text { pacientes jóvenes intolerantes a la lactosa de } 16 \text { a } 30 \\
\text { años del grupo al que se le administra leche deslactosada } \\
\text { y el grupo al que se le administra leche sin lactosa del } \\
\text { Hospital Hipólito Unanue en el } 2015 \text { ? } \\
\text { Problema Específicos } \\
\text { ¿Cuál es la frecuencia de los síntomas y signos } \\
\text { característicos de la intolerancia a la lactosa en los } \\
\text { pacientes de } 16 \text { a } 30 \text { años en el grupo al que se le } \\
\text { administra leche deslactosada del Hospital Hipólito } \\
\text { Unanue en el } 2015 \text { ? ¿Cuál es la frecuencia de los síntomas y signos } \\
\text { característicos de la intolerancia a la lactosa en los } \\
\text { pacientes de } 16 \text { a } 30 \text { años en el grupo al que se le } \\
\text { administra leche sin lactosa del Hospital Hipólito Unanue } \\
\text { en el } 2015 ?\end{array}$ & $\begin{array}{l}\text { Objetivo General } \\
\text { Evaluar si existen diferencias de los síntomas y } \\
\text { signos característicos de la intolerancia a la lactosa } \\
\text { en los pacientes de } 16 \text { a } 30 \text { años de los grupos al que } \\
\text { se le administra leche deslactosada y al que se le } \\
\text { administra leche sin lactosa en el Hospital Hipólito } \\
\text { Unanue en el } 2015 \text {. } \\
\text { Objetivos específicos } \\
\text { 1.- Determinar la frecuencia de los síntomas y signos } \\
\text { característicos de la intolerancia a la lactosa en los } \\
\text { pacientes de } 16 \text { a } 30 \text { años en el grupo al que se le } \\
\text { administra leche deslactosada en el Hospital Hipólito } \\
\text { Unanue en el } 2015 \text {. } \\
\text { 2.- Discriminar los síntomas y signos característicos } \\
\text { de la intolerancia a la lactosa en los pacientes de } 16 \\
\text { a } 30 \text { años en el grupo al que se le administra leche } \\
\text { sin lactosa en el Hospital Hipólito Unanue en el } 2015 \text {. } \\
\text { 3.- Conocer las características sociodemográficas de } \\
\text { los pacientes de } 16 \text { a } 30 \text { años en los grupos de }\end{array}$ & $\begin{array}{l}\text { Hipótesis Generales: } \\
\text { H1: La diferencia de los síntomas } \\
\text { característicos de la intolerancia a la } \\
\text { lactosa en los pacientes del grupo al } \\
\text { que se le administró leche } \\
\text { deslactosada al } 15 \% \text { y el grupo al que } \\
\text { se le administró leche sin lactosa es } \\
\text { inferior al } 10 \% \text {. } \\
\text { H0: La diferencia de los síntomas } \\
\text { característicos de la intolerancia a la } \\
\text { lactosa en los pacientes del grupo al } \\
\text { que se le administró leche } \\
\text { deslactosada y el grupo al que se le } \\
\text { administró leche sin lactosa es superior } \\
\text { o igual al } 10 \% \quad\end{array}$ & $\begin{array}{l}\text { Variable de intervención: } \\
\text { leche deslactosada } \\
\text { conteniendo } 15 \% \text { de } \\
\text { lactosa. } \\
\text { Variable control: leche } \\
\text { sin lactosa. } \\
\text { Variable Dependiente: } \\
\text { Síntomas y signos de } \\
\text { intolerancia a la lactosa }\end{array}$ \\
\hline
\end{tabular}




\begin{tabular}{|c|c|}
\hline $\begin{array}{l}\text { - ¿Cuáles son las características sociodemográficas de los } \\
\text { pacientes de } 16 \text { a } 30 \text { años en los grupos de intervención y } \\
\text { de control del Hospital Hipólito Unanue en el } 2015 ?\end{array}$ & $\begin{array}{l}\text { intervención y de control en el Hospital Hipólito } \\
\text { Unanue en el } 2015 \text {. }\end{array}$ \\
\hline
\end{tabular}

\begin{tabular}{|c|c|c|c|}
\hline DISEÑO & POBLACIÓN Y MUESTRA & TECNICAS E INSTRUMENTOS & ESTADISTICA \\
\hline $\begin{array}{l}\text { - Según el objetivo: El estudio es de tipo analítico ya que se } \\
\text { estableció una relación causa efecto mediante una } \\
\text { intervención con leche deslactosada y observar los efectos } \\
\text { en los síntomas de intolerancia a la lactosa. } \\
\text {-Según el control de la variable independiente: El estudio } \\
\text { experimental cuyo diseño fue de un ensayo clìnico } \\
\text { aleatorizado doble ciego de equivalencia, cuya intervención } \\
\text { fue (leche deslactosada conteniendo 15\% de lactosa) para } \\
\text { observar su efecto sobre una variable de respuesta. } \\
\text {-Según el número de mediciones: El estudio es longitudinal } \\
\text { porque la variable de respuesta se evaluó después de la } \\
\text { intervención. } \\
\text {-Según la direccionalidad: El estudio es prospectivo ya que } \\
\text { los datos utilizados ocurrieron después del inicio del estudio. }\end{array}$ & $\begin{array}{l}\text { Población objetivo. } \\
\text { Jóvenes adultos de } 16 \text { a } 30 \text { años intolerantes a la } \\
\text { lactosa de la ciudad de Lima. } \\
\text { Población en estudio. } \\
\text { Pacientes jóvenes adultos de } 16 \text { a } 30 \text { años que han } \\
\text { sido diagnosticados como intolerantes a la lactosa y } \\
\text { que asisten al consultorio externo de } \\
\text { Gastroenterología del Hospital Hipólito Unanue. }\end{array}$ & $\begin{array}{l}\text { El instrumento para la obtención de la } \\
\text { información se realizará mediante una } \\
\text { fuente de información primaria } \\
\text { utilizando la técnica de un cuestionario } \\
\text { aplicado directamente a los jóvenes } \\
\text { adultos intolerantes y sometidos a una } \\
\text { prueba piloto. }\end{array}$ & $\begin{array}{l}\text { La información } \\
\text { recopilada se analizó y } \\
\text { procesó con el programa } \\
\text { estadístico de SPP } \\
\text { versión 22, se realizó una } \\
\text { estadística descriptiva de } \\
\text { datos de consumo } \\
\text { usando un análisis de } \\
\text { frecuencias, medidas de } \\
\text { tendencia central y de } \\
\text { variabilidad, para el } \\
\text { contraste de la prueba de } \\
\text { hipótesis se utilizó la } \\
\text { prueba de t- student. }\end{array}$ \\
\hline
\end{tabular}




\section{JUICIO DE EXPERTOS}

\begin{tabular}{|c|c|c|c|c|c|c|}
\hline Ítems & Juez 1 & Juez 2 & Juez 3 & Juez 4 & Juez 5 & p valor \\
\hline 1 & 1 & 1 & 1 & 1 & 1 & 0.03125 \\
\hline 2 & 1 & 0 & 1 & 1 & 1 & 0.15625 \\
\hline 3 & 1 & 0 & 1 & 1 & 1 & 0.15625 \\
\hline 4 & 1 & 1 & 1 & 1 & 1 & 0.03125 \\
\hline 5 & 1 & 1 & 1 & 1 & 1 & 0.03125 \\
\hline 6 & 1 & 1 & 1 & 1 & 0 & 0.15625 \\
\hline 7 & 1 & 1 & 1 & 1 & 1 & 0.03125 \\
\hline 8 & 1 & 1 & 1 & 1 & 1 & 0.03125 \\
\hline 9 & 1 & 1 & 1 & 1 & 1 & 0.03125 \\
\hline 10 & 0 & 1 & 1 & 1 & 1 & 0.15625 \\
\hline 11 & 1 & 1 & 1 & 1 & 1 & 0.03125 \\
\hline 12 & 1 & 1 & 1 & 1 & 1 & 0.03125 \\
\hline
\end{tabular}

Ho: La proporción de los jueces que dicen "Si" es igual a la de los jueces que dicen "No". Es decir entre los jueces no hay concordancia. La probabilidad de éxito es de $50 \%$.

Ha: La proporción de los jueces es diferente de 0.5. Si hay concordancia entre los jueces.

Porcentaje de acuerdos entre los jueces:

$\mathrm{b}=\mathrm{Ta} / \mathrm{Ta}+\mathrm{Tb}$

$b=$ Grado de coincordancia entre los jueces

$\mathrm{Ta}=$ Total de acuerdos

$\mathrm{Tb}=$ Total de desacuerdos $b=56 / 60 \times 100 \%=93,3 \%$

El resultado es que el $\mathbf{9 3 , 3 \%}$ de respuestas de los jueces concuerdan 